\title{
Influence of sub-cloud secondary evaporation and moisture sources on stable isotopes of precipitation in Shiyang River BasinखNorthwest China
}

\section{Hui Xiong}

College of Geography and Environment Science, Northwest Normal University, Lanzhou, 730070 Wenxiong Jia ( $\square$ wxjiaxy@163.com )

College of Geography and Environment Science, Northwest Normal University, Lanzhou, 730070 Guofeng Zhu

College of Geography and Environment Science, Northwest Normal University, Lanzhou, 730070

\section{Yang Shi}

College of Geography and Environment Science, Northwest Normal University, Lanzhou, 730070

\section{Zhiyuan Zhang}

College of Geography and Environment Science, Northwest Normal University, Lanzhou, 730070

\section{Le Yang}

College of Geography and Environment Science, Northwest Normal University, Lanzhou, 730070

\section{Miaomiao Zhang}

College of Geography and Environment Science, Northwest Normal University, Lanzhou, 730070

\section{Fuhua Zhang}

College of Geography and Environment Science, Northwest Normal University, Lanzhou, 730070

\section{Research Article}

Keywords: Shiyang River Basin, precipitation, stable isotope, sub-cloud secondary evaporation, moisture sources

Posted Date: March 2nd, 2021

DOl: https://doi.org/10.21203/rs.3.rs-275529/v1

License: (9) (1) This work is licensed under a Creative Commons Attribution 4.0 International License. Read Full License 


\title{
1 Influence of sub-cloud secondary evaporation and moisture
}

2 sources on stable isotopes of precipitation in Shiyang River

3 Basin, Northwest China

4 Hui Xiong ${ }^{1}$, Wenxiong Jia ${ }^{1, *}$, Guofeng Zhu ${ }^{1,2}$, Yang Shi ${ }^{1}$, Zhiyuan Zhang ${ }^{1}$, Le Yang ${ }^{1}$, Miaomiao

$5 \quad$ Zhang $^{1}$, Fuhua Zhang ${ }^{1}$

$6{ }^{1}$ College of Geography and Environment Science, Northwest Normal University, Lanzhou, 730070,

7 China

$8{ }^{2}$ State Key Laboratory of Cryosphere Sciences, Northwest Institute of Eco-Environment and

9 Resources, Chinese Academy of sciences, Lanzhou, 730000, China

$10 *$ Corresponding author: wxjiaxy@163.com(W.J.);

\begin{abstract}
The fractionation of stable isotopes in precipitation runs through all links of the hydrological cycle. Studying its composition will help to understand the hydrological cycle process and the interaction between land and atmosphere. Based on the data of measured precipitation isotopes and related meteorological elements from 11 sampling points from January 2018 to September 2019, the existence of sub-cloud secondary evaporation is verified. Used the water vapor flux and the improved Lagrangian model, the moisture source affecting precipitation is tracked. On the basis of them, the influence of sub-cloud secondary evaporation and moisture sources on stable isotopes of precipitation is analyzed. The results show that the sub-cloud secondary evaporation exists in the Shiyang River Basin, and it is stronger in spring and summer than that in autumn and winter, which makes the stable isotopes of precipitation higher in summer and lower in winter. Besides, the sub-cloud secondary evaporation is stronger in the midstream and downstream, which results in the heavy isotopes of precipitation are generally more enriched. In the vertical direction, the secondary evaporation between $850 \mathrm{hPa}$ and 700 $\mathrm{hPa}$ is the strongest, which makes heavy isotopes enrich and $d$-excess decreases in this layer. The moisture source of precipitation in the Shiyang River Basin is dominated by westerly air masses, that mid-high latitude continental sources have a large contribution to precipitation but the supply of sea sources is very limited, which makes the $d$-excess of precipitation is higher and does not show regional consistency and seasonality well.
\end{abstract}

Keywords: Shiyang River Basin; precipitation; stable isotope; sub-cloud secondary evaporation; moisture sources

\section{Introduction}

As a natural source tracer, stable isotopes of precipitation can not only record water information but also reflect changes in climate and the environment ${ }^{1}$. Observation and research on stable isotopes of 
precipitation began as early as the $1950 \mathrm{~s}^{2}$. In 1961, the World Meteorological Organization (WMO) and the International Atomic Energy Agency (IAEA) established the Global Network of Isotopes in Precipitation (GNIP) to provide basic data for related researches. Craig found that there is a linear relationship between $\delta \mathrm{D}$ and $\delta^{18} \mathrm{O}$ in precipitation $\left(\delta \mathrm{D}=8 \delta^{18} \mathrm{O}+10\right)$, which is the Global Meteoric Water Line $(\mathrm{GMWL})^{3}$. However, due to the different environmental conditions in different regions, the slope and intercept of the meteoric water line are somewhat different from GMWL. To quantify this difference, Dansgaard proposed the concept of deuterium excess ( $d$-excess) $\left(d=\delta \mathrm{D}-8 \delta^{18} \mathrm{O}\right)^{4}$. The dynamic and thermal fractionations of the isotope are reflected in the processes of evaporation, condensation, transportation, and precipitation. Usually, water molecules containing heavy isotopes in the liquid phase have stronger binding energy and lower diffusion speed, which makes heavy isotopes less likely to evaporate than light isotopes ${ }^{5}$. Although the ratio of hydrogen and oxygen isotope changes linearly, this linear relationship also has a deviation from the equilibrium state, which is manifested as a change of $d$-excess in precipitation ${ }^{6}$. Previous studies have pointed out that the $d$-excess in the northern hemisphere should be lower in summer and higher in winter ${ }^{7}$, but the increase of dry inland water vapor or the evaporation of raindrops from the cloud bottom to the ground (sub-cloud secondary evaporation) also change the $d$-excess in precipitation ${ }^{8,9,10}$. Therefore, analyzing the influence of sub-cloud secondary evaporation and moisture sources on stable isotopic of precipitation is an indispensable content for regional hydrological cycle research.

Using experimental methods, Stewart calculated the influence of evaporation on stable isotopes in raindrops under different ambient gas and meteorological conditions ${ }^{11}$. Froehlich et al simulated and established a raindrop evaporation model to study the effect of sub-cloud secondary evaporation ${ }^{12}$. After that, related researchers have proposed different methods for improving the raindrop evaporation model. Using several standard isobaric surfaces as the dividing line in the falling process of raindrops, Guan et al divided the atmosphere into several homogeneous horizon combinations to calculate the sub-cloud secondary evaporation ${ }^{13}$. This can more accurately characterize the evaporation experienced during the fall of raindrops. To reduce the deviation, Wang et al set variables that used measured data to replace the fixed parameters in the Froehlich model ${ }^{14}$. This improved method uses the air in which raindrops fall from the cloud bottom to the ground as a homogeneous form, and uses conventional ground parameters as the variable input. At present, most studies on sub-cloud secondary evaporation are based on homogeneous assumptions, but the atmospheric parameters from high altitude to the ground are neither homogeneous nor uniform. Therefore, it is more reasonable that the calculation combines the stratification assumption with the measured data. This method has been applied to research in Xinjiang ${ }^{15}$ and Australia ${ }^{13}$. There are many research methods on the sources of precipitation, such as Hysplit and Flexpart models, isotope analysis, and Euler methods ${ }^{16,17}$. The analysis method of Hysplit backward trajectory based on the Lagrangian model is used widely because it can provide a better technical approach for studying the moisture transportation process and obtain the main source direction and proportion by cluster analysis. Sodemann et al ${ }^{18}$ and Crawford et $\mathrm{al}^{19}$ improved the traditional backward trajectory based on Lagrangian, which considers the meteorological elements on the model trajectory and corrects the backward trajectory of moisture by using specific humidity. This method has been applied to the analysis of moisture sources for Short-time Heavy Rainfall in Xinjiang ${ }^{20}$. 
The Shiyang River Basin is deep in the hinterland of the Eurasian continent, where the formation and transformation of water resources and the hydrological cycle process are complex ${ }^{21}$. As one of three major inland river basins in Gansu Province, the water supply mainly comes from mountain precipitation and meltwater. Due to global climate warming that led to the decrease of glacier reserves and precipitation, coupled with the increase of population and rapid development of economy and society, the over-extraction of groundwater is serious in the basin. The decline of water conservation capacity caused by the destruction of vegetation in the upper Qilian Mountains and the increase of irrigation water in the midstream oasis lead to the amount of surface water entering the downstream Oasis decrease. Because the contradiction between supply and demand of water has become increasingly prominent, the problem of desertification is very serious ${ }^{22,23}$. Therefore, changes in hydrological processes caused by precipitation and snowmelt are related to the redistribution of regional water resources and water security. This study analyzes the influence of the sub-cloud secondary evaporation and moisture source on the stable isotopic of precipitation, which can reveal the hydrological process and water balance mechanism of the Shiyang River Basin, and provide a theoretical basis for the scientific management and utilization of water resources and the protection and restoration of ecological environment in the basin.

\section{Data and methods}

\section{Study area}

The Shiyang River Basin is located in the eastern part of Hexi Corridor in Gansu Province and the northern slope of the Qilian Mountains $\left(101^{\circ} 41^{\prime}-104^{\circ} 16^{\prime} \mathrm{E}, 36^{\circ} 29^{\prime}-39^{\circ} 27^{\prime} \mathrm{N}\right)$. The basin area is $4.16 \times 10^{4} \mathrm{~km}$ and the altitude is $1254 \mathrm{~m}-5125 \mathrm{~m}$. The terrain is higher in the south than the north, and it slopes from southwest to northeast. The natural environment in the Shiyang River Basin is quite different, it can be divided into four major geomorphological units from south to north: the Qilian Mountains, the corridor plain, the northern low hills and the deser $\mathrm{t}^{24}$. The Shiyang River Basin is located in the transitional area between the monsoon area and the arid area, with short and hot summer, long and cold winter, large temperature difference, small precipitation, strong evaporation, and dry air. From south to north, it can be divided into three climate zones: the alpine semi-arid and semi-humid area in the southern Qilian Mountains, with an average annual temperature of $2-6^{\circ} \mathrm{C}$, annual precipitation of more than $300 \mathrm{~mm}$, and annual evaporation of 700-1200 $\mathrm{mm}$; the cool and arid area in the central corridor plain, with the annual average temperature of $6-8^{\circ} \mathrm{C}$, the annual precipitation of 150-300 mm, and the annual evaporation of 1200-2000 mm; the warm and arid area in the north, with the annual average temperature of more than $8{ }^{\circ} \mathrm{C}$, the annual precipitation of less than $150 \mathrm{~mm}$, and the annual evaporation of more than $2000 \mathrm{~mm}^{25,26}$. Shiyang River originates from Daxue Mountain on the north side of Lenglongling in the eastern section of the Qilian Mountains, with an average annual runoff of $15.6 \times 10^{8} \mathrm{~m}^{327}$. It is supplied mainly by precipitation (91.2\%), and also contains alpine meltwater $(3.6 \%)^{28}$, which is concentrated mainly in summer and autumn ${ }^{29}$. After going northward, it flows through the corridor plain and Minqin Oasis and disappears gradually in the desert on the northern margin of the basin (Fig. 1). 


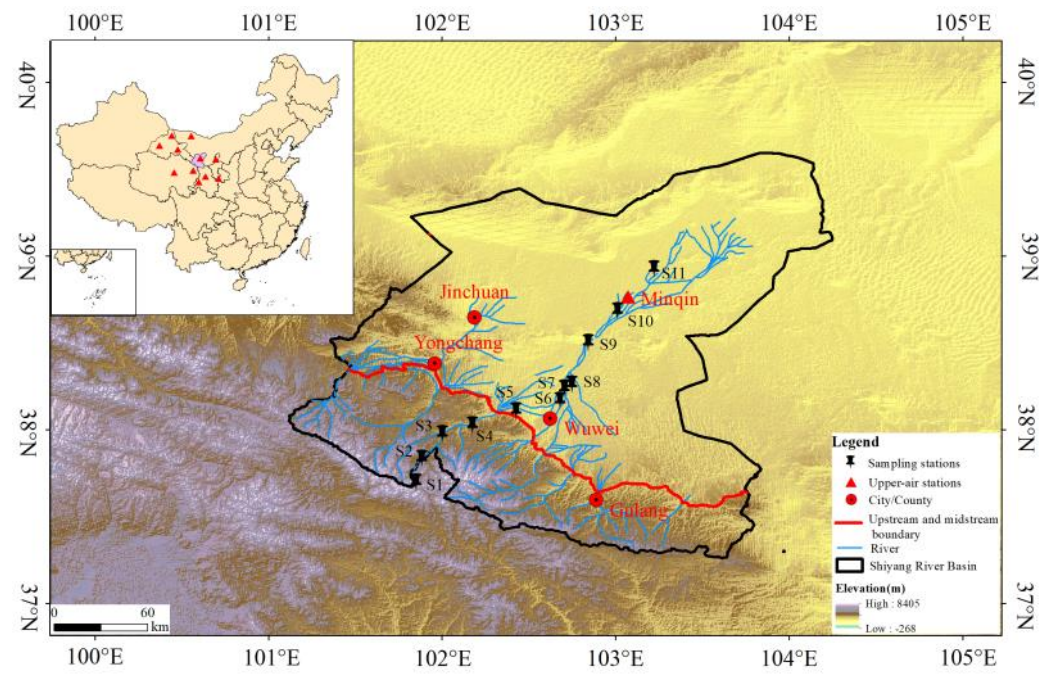

Fig.1 Map showing the locations of sampling sites in the Shiyang River Basin, which are labeled as upstream: Lenglongling (S1),

Hulinzhan (S2), Hujianxiang(S3), Xiyingwugou(S4), and midstream and downstream: Xiyingzhen(S5), Yangxiaba(S6),

\section{Sample collection and data sources}

\section{Collection and processing of precipitation sample}

As shown in Fig. 1, this study selected 11 collection points of precipitation sample in the Shiyang River Basin, and the sampling period is from January 2018 to September 2019. All precipitation samples were collected by the definition of precipitation events stipulated by meteorological observation, sealed in polyethylene sampling bottles, and stored in cold storage. Using the automatic weather observation instruments, the data of temperature, dew point, relative humidity, and atmospheric pressure were also collected. A total of 670 precipitation samples was transported to the isotope laboratory of the College of Geography and Environmental Sciences of Northwest Normal University for testing and analysis. The testing instrument is the DLT-100 liquid water isotope analyzer developed by Los Gatos Research in the United States, and the measurement result is expressed by the difference between the test sample isotope ratio and the standard sample ratio (\%):

$$
\delta^{18} \mathrm{O}(\text { or } \delta D)=\left(R_{S} / R_{V-S M O W}-1\right) \times 1000
$$

Where $R_{s}$ is the ratio of ${ }^{18} \mathrm{O} /{ }^{16} \mathrm{O}$ in the precipitation sample, and $R_{v-S M O W}$ is the ratio of ${ }^{18} \mathrm{O} /{ }^{16} \mathrm{O}$ in the Vienna Standard Mean Ocean Water.

\section{Other data sources}

As shown in Fig. 1, this study selected the meteorological data of 11 upper-air stations near the Shiyang River Basin (Minqin, Yuzhong, Kongtong, Hezuo, Jiuquan, Dunhuang, Mazongshan, Xining, Dulan, Yinchuan, Ejinaqi) (https: //www.ncdc.noaa.gov), and used Inverse Distance Weighting (IDW) to correspond the upper-air stations to the ground sampling points. The reanalyzing data comes from NCEP/NCAR $\left(2.5^{\circ} \times 2.5^{\circ}\right)$ of Physical Sciences Laboratory of the National Ocean and Atmospheric 
Administration of the United States (NOAA) (https:/www.psl.noaa.gov). The backward trajectory data comes from the Global Data Assimilation System (GDAS) (ftp://arlftp.arlhq.noaa.gov) operated by the National Environmental Forecast Center of the United States and used the United States National Ocean and Hybrid Single-Particle Lagrangian Integrated Trajectory (HYSPLIT) developed by the Atmospheric Resources Laboratory of the NOAA to track moisture source.

\section{Method}

\section{Local meteoric water line}

The method of ordinary least squares ${ }^{30}$ is used to calculate the local meteoric water line (LMWL), and the slope $(a)$ and intercept $(b)$ are respectively:

$$
\begin{aligned}
& a=\frac{\sum_{i=1}^{n} x y-(1 / n) \sum_{i=1}^{n} x \sum_{i=1}^{n} y}{\sum_{i=1}^{n} x^{2}-(1 / n)\left(\sum_{i=1}^{n} x\right)^{2}} \\
& b=(1 / n) \sum_{i=1}^{n} y-(a / n) \sum_{i=1}^{n} x
\end{aligned}
$$

Where $n$ is the number of samples, $x$ is the $\delta^{18} \mathrm{O}$, and $y$ is the $\delta \mathrm{D}$.

The theoretical slope $\left(S_{T}\right)$ of the LMWL is calculated based on the condensation temperature ${ }^{31}$ :

$$
S_{T}=\frac{\left({ }^{2} \alpha-1\right)(1000+\delta D)}{\left({ }^{18} \alpha-1\right)\left(1000+\delta^{18} O\right)}
$$

Where ${ }^{2} \alpha$ and ${ }^{18} \alpha$ are the equilibrium fractionation coefficients of hydrogen and oxygen isotopes between water and gas, respectively ${ }^{32}$.

\section{Raindrop evaporation model of improved STEWART}

Due to the sub-cloud secondary evaporation, there are some differences in the isotopes between the raindrops at the cloud bottom and the raindrops falling on the ground $(\Delta d)$. In this study, two methods are used to calculate the sub-cloud secondary evaporation. They are the Stewart raindrop evaporation model $^{11,12}$, but the calculation of several parameters is different. The formula as follows:

$$
\Delta d=\left(1-^{2} \gamma /^{2} \alpha\right)\left(f^{2} \beta-1\right)-8\left(1-{ }^{18} \gamma /^{18} \alpha\right)\left(f^{18} \beta-1\right)
$$

Where ${ }^{2} \gamma,{ }^{18} \gamma,{ }^{2} \beta$, and ${ }^{18} \beta$ are defined by Stewart ${ }^{11} ;{ }^{2} \alpha$ and ${ }^{18} \alpha$ are the same as formula (4); $f$ is the proportion of the remaining mass of raindrops after evaporation during falling ${ }^{14}$. The $f$ can be calculated as: 


$$
f=\frac{m_{\text {end }}}{m_{\text {end }}+m_{e v}}
$$

Where $m_{\text {end }}$ is the mass of the raindrop touching the ground; $m_{e v}$ is the mass lost by evaporation. $m_{e v}$ can be expressed by the raindrop evaporation rate $\left(r_{e v}\right)$ multiply the raindrop landing time $(t)$, where the $t$ is used the cloud base height $(H)$ and the terminal velocity of raindrops $\left(v_{e n d}\right)$ to calculate. The $H$ is calculated by the Laplace pressure formula ${ }^{33}$ :

$$
H=18400\left(1+T_{\text {mean }} / 273\right) \lg \left(P / P_{L C L}\right)
$$

Where $T_{\text {mean }}$ is the average temperature between the lifting condensation level (LCL) and the ground $\left({ }^{\circ} \mathrm{C}\right) . P$ and $P_{\mathrm{LCL}}$ are the pressure $(\mathrm{hPa})$ at the ground and the LCL, respectively.

According to Kinzer et $\mathrm{al}^{34}$, the $r_{e v}$ can be calculated as:

$$
r_{e v}=Q_{1} Q_{2}
$$

Where $Q_{1}$ is a function (cm) of temperature $(T)$ and raindrop diameter $(D) ; Q_{2}$ is a function $\left(\mathrm{g} \cdot \mathrm{cm}^{-1} \cdot \mathrm{s}^{-1}\right)$ of $T$ and relative humidity $(R H)$. Based on the data obtained by Kinzer et $\mathrm{al}^{34}$, this study used bilinear interpolation to obtain $Q_{1}$ and $Q_{2}$ under different meteorological conditions.

Best proposed that the distribution of raindrop diameter of global rainfall conforms to the following empirical formula ${ }^{35}$ :

$$
1-F=\mathrm{e}^{-\left(D / A I^{P}\right)^{n}}
$$

Where $e$ is the natural constant; $I$ is the precipitation intensity $\left(\mathrm{mm} \cdot \mathrm{h}^{-1}\right) ; F$ is the cumulative volume percentage of raindrops with a diameter less than $D$ in the atmosphere.

The two methods used to calculate the sub-cloud secondary evaporation are based on the improved Stewart model. The $D$ in the stratification hypothesis is based on the raindrop diameter of the ground to calculate the raindrop diameter of the cloud base through the iterative calculation:

$$
D_{\mathrm{c}}=\sqrt[3]{\frac{6\left(m_{\text {end }}+m_{\text {ev }}\right)}{\pi \rho}}
$$

Where $D_{c}$ is the diameter of raindrops at cloud base; $m_{e n d}$ and $m_{e v}$ are the same as formula (6); $\rho$ is the density of water.

\section{Results and analysis}

\section{Local meteoric water line}


Similar to the GMWL, the relationship between $\delta \mathrm{D}$ and $\delta^{18} \mathrm{O}$ in precipitation in a certain area is called the LMWL. The slope of the meteoric water line is composed of the ratio of the fractionation rates of the $\delta \mathrm{D}$ and $\delta^{18} \mathrm{O}$, which can reflect the fractionation effects between them, and the intercept of its can reflect the deviation degree of $\delta \mathrm{D}$ from the equilibrium state ${ }^{36}$. Relevant studies have shown that precipitation affected by the sub-cloud secondary evaporation will deplete the lighter isotope but enrich the heavy isotope ${ }^{37}$, which makes the slope and intercept of the meteoric water line decrease. So the changes of the slope and intercept of the LMWL under different meteorological conditions are considered to evaluate the intensity of sub-cloud secondary evaporation ${ }^{38,39}$.

Table 1 Local meteoric water line at each sampling point in Shiyang River Basin

\begin{tabular}{|c|c|c|c|c|c|c|c|c|c|c|c|}
\hline Station & Longtitude/E & Latitude/N & Altitude/m & $\begin{array}{c}\text { Number of } \\
\text { samples }\end{array}$ & Research period & $\begin{array}{l}\text { Mean } \\
\delta \mathrm{D} / \%\end{array}$ & $\begin{array}{c}\text { Mean } \\
\delta^{18} \mathrm{O} / \%\end{array}$ & $\begin{array}{c}\text { intercept } \\
\quad / \% 0\end{array}$ & slope & $r^{2}$ & $S_{T}$ \\
\hline Lenglongling & $101.86^{\circ}$ & $37.56^{\circ}$ & 3653 & 188 & $2018 / 01-2019 / 08$ & -68.19 & -10.26 & 12.70 & 7.88 & 0.98 & 8.87 \\
\hline Hulinzhan & $101.86^{\circ}$ & $37.69^{\circ}$ & 2720 & 65 & $2018 / 03-2019 / 08$ & -43.62 & -7.16 & 11.65 & 7.69 & 0.97 & 8.78 \\
\hline Huajianxiang & $102.01^{\circ}$ & $37.84^{\circ}$ & 2324 & 150 & 2018/01-2019/09 & -52.54 & -7.80 & 7.70 & 7.72 & 0.99 & 8.61 \\
\hline Xiyingwugou & $102.18^{\circ}$ & $37.89^{\circ}$ & 2096 & 72 & $2018 / 01-2019 / 10$ & -78.40 & -11.29 & 11.15 & 7.93 & 0.99 & 8.58 \\
\hline Xiyingzhen & $102.43^{\circ}$ & $37.97^{\circ}$ & 1748 & 43 & $2018 / 05-2019 / 04$ & -46.30 & -6.77 & 3.64 & 7.38 & 0.98 & 8.52 \\
\hline Yangxiaba & $102.69^{\circ}$ & $38.03^{\circ}$ & 1489 & 23 & $2018 / 05-2019 / 01$ & -29.57 & -4.49 & 1.10 & 6.82 & 0.97 & 8.41 \\
\hline Dengjiazhuang & $102.71^{\circ}$ & $38.10^{\circ}$ & 1468 & 15 & $2019 / 07-2019 / 10$ & -60.15 & -8.89 & 11.25 & 8.04 & 0.98 & 8.38 \\
\hline Jiuduantan & $102.75^{\circ}$ & $38.12^{\circ}$ & 1464 & 25 & $2018 / 05-2019 / 09$ & -31.77 & -5.42 & 3.68 & 5.18 & 0.75 & 8.48 \\
\hline Hongqigu & $102.85^{\circ}$ & $38.36^{\circ}$ & 1421 & 19 & $2019 / 04-2019 / 10$ & -34.28 & -5.53 & 0.77 & 6.34 & 0.89 & 8.43 \\
\hline Xuebaizhen & $103.02^{\circ}$ & $38.55^{\circ}$ & 1387 & 13 & $2018 / 05-2018 / 10$ & -37.54 & -6.14 & 1.99 & 6.44 & 0.96 & 8.36 \\
\hline Datanxiang & $103.23^{\circ}$ & $38.79^{\circ}$ & 1348 & 57 & 2018/04-2019/09 & -47.08 & -7.03 & 4.22 & 7.29 & 0.96 & 8.19 \\
\hline
\end{tabular}

Table 1 reflects the mean of $\delta \mathrm{D}$ and $\delta^{18} \mathrm{O}$ at different sampling points during the research period, as well as the slope and intercept of the LMWL. By comparing the mean of $\delta \mathrm{D}$ and $\delta^{18} \mathrm{O}$ at each sampling point, it can be seen that the $\delta \mathrm{D}$ and $\delta^{18} \mathrm{O}$ of the Shiyang River Basin generally show a decreasing trend with altitude increase. This result is consistent with the previous studies ${ }^{40}$. Affected by the condensing temperature, the source and transport path of moisture, and the weather system during precipitation $^{41}$, the slope and intercept of the LMWL are different. Although the altitude of Xiyingwugou is lower than other sampling points of the upstream, the mean of $\delta \mathrm{D}$ and $\delta^{18} \mathrm{O}$ is the lowest. This may be due to the fact that the sampling point is close to the reservoir and is affected by the combined influence of moisture recirculation intensity, relative humidity, and temperature, which masks the elevation effect of the stable isotope.

According to the results in Table 1, it can be seen that the slopes and intercepts of the LMWL at 
sampling plots in the Shiyang River Basin deviate to a certain extent from the GMWL. The slope of

209 LMWL less than 8 indicates that the precipitation process occurs under non-Rayleigh conditions ${ }^{42}$. In

210 this study, the slopes of the LMWL except for the sampling point of Dengjiazhuang are below 8,

211 indicating that the Shiyang River Basin has a dry climate and raindrops are affected by sub-cloud

212 secondary evaporation. Compared with the slope, the intercept change of the LMWL is more

213 complicated, which is related to the degree of fractionation. The factors that affect fractionation include

214 humidity, temperature, and wind speed. Generally, high temperature and low relative humidity make

215 the isotopes of precipitation more deviate from the equilibrium state, which results in the intercept of

216 LMWL decrease ${ }^{43}$. Except for Lenglongling, Hulinzhan, Xiyingwugou, and Dengjiazhuang, the

217 intercepts of the LMWL at other sampling points are much lower than the GMWL, which reflects that

218 there is sub-cloud secondary evaporation in the Shiyang River Basin ${ }^{44}$. At the same time, the $S_{T}$ of each

219 sampling point is greater than 8 and greater than the slope of the LMWL, which also shows that there

220 exists sub-cloud secondary evaporation in the Shiyang River Basin ${ }^{45}$. Besides, the slopes of most

221 sampling points in the midstream and downstream are lower than those in the upstream, indicating that

222 the sub-cloud secondary evaporation is stronger in the midstream and downstream than in the

223 upstream.

\section{Sub-cloud secondary evaporation}

225 Based on the measured meteorological elements of 11 sampling points, assumed the atmosphere of 226 raindrops falling from the cloud base to the ground as a homogeneous form, and used the measured 227 meteorological data of ground sampling points as input parameters, the sub-cloud secondary 228 evaporation was calculated at different sampling points (Table 2). Relevant studies have shown that 229 temperature, relative humidity, raindrop landing height, and raindrop diameter have a certain impact on 230 the strength of the sub-cloud secondary evaporation ${ }^{11,46,47}$. Therefore, this study focuses on the 231 environmental factors to clarify their impact on the sub-cloud secondary evaporation.

Table 2 Sub-cloud secondary evaporation and environmental factors in Shiyang River Basin

\begin{tabular}{ccccccc}
\hline Station & $T /{ }^{\circ} \mathrm{C}$ & $R H / \%$ & $D / \mathrm{mm}$ & $H / \mathrm{m}$ & $f / \%$ & $\Delta d / \%$ o \\
\hline Lenglongling & 3.23 & 71.77 & 0.85 & 577.77 & 76.97 & -3.03 \\
Hulinzhan & 10.12 & 73.74 & 0.94 & 568.88 & 78.72 & -2.39 \\
Huajianxiang & 12.22 & 60.07 & 1.11 & 968.38 & 68.71 & -4.14 \\
Xiyingwugou & 7.81 & 69.88 & 0.94 & 649.54 & 73.74 & -3.69 \\
Xiyingzhen & 15.3 & 60.73 & 0.84 & 980.65 & 51.36 & -12.39 \\
Yangxiaba & 16.07 & 58.71 & 0.93 & 1038.14 & 53.33 & -9.89 \\
Jiuduntan & 21.34 & 69.71 & 1.18 & 762.26 & 72.12 & -2.83
\end{tabular}




$\begin{array}{ccccccc}\text { Xuebaizhen } & 21.12 & 69.19 & 1.01 & 773.20 & 67.00 & -4.71 \\ \text { Hongqigu } & 20.02 & 62.6 & 1.32 & 1006.48 & 70.42 & -3.88 \\ \text { Datanxiang } & 23.36 & 68.44 & 0.94 & 818.85 & 60.82 & -4.21\end{array}$

From the results in Table 2, it can be seen that the changing trend of $f$ and $\Delta d$ is basically the same, and the $f$ of most sampling points in the midstream and downstream is smaller than that in the upstream (except for Hongqigu, Dengjiazhuang, Jiuduntan). This indicates that the sub-cloud secondary evaporation in the midstream and downstream is stronger than that in the upstream, which is consistent with the results of the LMWL. Comparing the environmental elements in table 2, it can be shown that the temperature in the midstream and downstream is higher than that in the upstream. This is mainly because the underlying surface causes temperature differences, that the upstream is mountainous but the downstream is desert. At the same time, the downstream belongs to an extremely arid area, where the precipitation is concentrate in summer and scarce or even no precipitation in winter, while the precipitation in the upstream is distributed in every season. Although the average raindrop diameter of most sampling point in the midstream and downstream is larger than that in the upstream, the lower altitudes, long time for raindrops to fall, temperature and precipitation conditions are favorable for evaporation, so the sub-cloud secondary evaporation of the former is stronger than that in the latter. The $f$ of Hongqigu is relatively larger in midstream and downstream. This is because of the influence of the Hongyashan Reservoir nearby, so the larger diameter of raindrops is not conducive to evaporation. The $f$ of Dengjiazhuang and Jiuduntan is also relatively larger. The reason is that the precipitation samples are mostly concentrated in summer with abundant precipitation, and the larger raindrop diameters, the higher relative humidity, the lower height of raindrops, and the short time for raindrops make the sub-cloud secondary evaporation weaker than other sampling plots in the midstream and downstream.

Under the influence of the sub-cloud secondary evaporation, the light isotopes are depleted and the heavy isotopes are enriched. In the Shiyang River Basin, the sub-cloud secondary evaporation in the upstream is weaker than that in the midstream and downstream, so the $\delta^{18} \mathrm{O}$ is more enriched in the former than that in the latter. This conclusion is consistent with previous research results ${ }^{48,49}$.

\section{Temporal and spatial changes of $d$-excess}

$d$-excess reflects the hydrogen and oxygen isotopic composition of the precipitation process. In addition to the sub-cloud secondary evaporation, it is also affected by meteorological indicators, such as sea surface temperature, wind speed, and relative humidity ${ }^{50,51}$. $d$-excess contains important information about the formation source of warm humid air masses related to precipitation, including the equilibrium or non-equilibrium of the entire evaporation process and the speed of the evaporation rate. The $d$-excess is decreased with the relative humidity of the moisture source enhancing ${ }^{36}$. The change of $d$-excess indicates the relative humidity of the moisture source to a certain extent and provides a basis for inferring the source of precipitation moisture. Therefore, this study divides the $d$-excess by time and region and further analyzes its change characteristics (Fig. 2). 


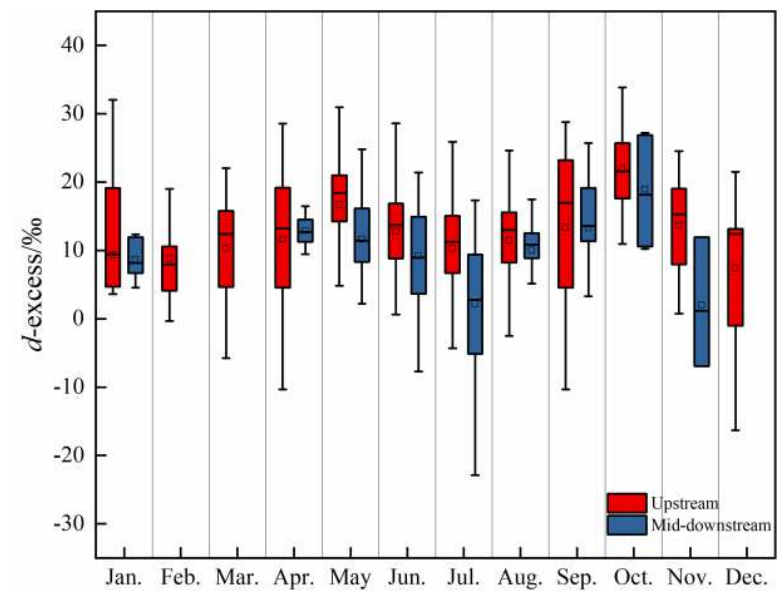

Fig. 2 Temporal and spatial changes of $d$-excess in Shiyang River Basin

As shown in Fig.2, the $d$-excess is no obvious seasonal variation in the Shiyang River Basin, and the overall trend is bimodal fluctuations. The specific manifestation is that the $d$-excess increases gradually from February to May and July to October, and decreases gradually from May to July and after October. The $d$-excess is relatively stable in winter half-year, and fluctuates greatly in summer half-year, indicating that the source of precipitation is more complicated in summer half-year. Besides, the $d$-excess in the midstream and downstream is lower than that in the upstream every month. Relevant studies have shown that the precipitation in the upstream is more affected by local recirculated water vapor, but the precipitation in the midstream and downstream is more affected by sub-cloud secondary evaporation ${ }^{40}$. The precipitation affected by sub-cloud secondary evaporation has a low $d$-excess, while the precipitation affected by local recycling has a high $d$-excess ${ }^{52}$. Therefore, the regional difference of the $d$-excess in the study area is related to the sub-cloud secondary evaporation and the recirculation of moisture. From February to May, because of the temperature rise and less precipitation, the dry moisture causes the $d$-excess increase. From May to July, the summer monsoon causes the relatively humid moisture increase, the temperature is higher and the sub-cloud secondary evaporation is stronger, which makes the $d$-excess decrease. From July to October, owing to the precipitation increase the $\delta \mathrm{D}$ and $\delta^{18} \mathrm{O}$ continue to deplete, and the $d$-excess increases gradually. After October, precipitation is scarce in the midstream and downstream, even there is no precipitation in December, February, and March, while it is dominated by solid precipitation in the upstream. The solid precipitation falling from the cloud base to the ground does not change the isotope ratio ${ }^{53}$, and the small liquid precipitation is still facing the exchange of moisture ${ }^{54,55}$, so the $d$-excess is relatively low in winter. Besides, the low $d$-excess of the study area in winter may also be related to the source of precipitation.

\section{Discussion}

\section{The sub-cloud secondary evaporation based on stratification assumption}

Due to the non-uniform variation of atmospheric elements from high altitude to the ground, the sub-cloud secondary evaporation will also vary in the vertical direction. In this study, according to the 
293 altitudes and pressure of the sampling point, three isobaric surfaces of $850 \mathrm{hPa}$ (approximately $1500 \mathrm{~m}$ ),

$294700 \mathrm{hPa}$ (approximately $3000 \mathrm{~m}$ ), and $500 \mathrm{hPa}$ (approximately $5500 \mathrm{~m}$ ) are selected as the dividing line

295 from the ground to the high altitude, and the atmosphere is divided correspondingly into several

296 homogeneous layer combinations. Based on the homogeneous assumption, the input parameters

297 required for each layer are calculated by iterative calculations, and the evaporation of raindrops falling

298 from the cloud base to the ground is calculated. Since the large differences in the geomorphology of the

299 sampling points in the study area, the altitude of them and the atmospheric pressure during the

300 precipitation period are considered comprehensively when using the stratification assumption. The

301 sampling points are divided into three groups for calculation: $\square$ The altitude of the sampling

302 point $>3000 \mathrm{~m}$ (Sampling point air pressure $<700 \mathrm{hPa}$ ); $\square 1500 \mathrm{~m}<$ sampling point altitude $<3000 \mathrm{~m}$

$303(700 \mathrm{hPa}<$ sampling point air pressure $<800 \mathrm{hPa}$ ); $\square$ Sampling point altitude $<1500 \mathrm{~m}$ (sampling point

304 air pressure $>850 \mathrm{hPa})$.

305

306

307

Table 3 Sub-cloud secondary evaporation and environmental factors based on stratification assumption

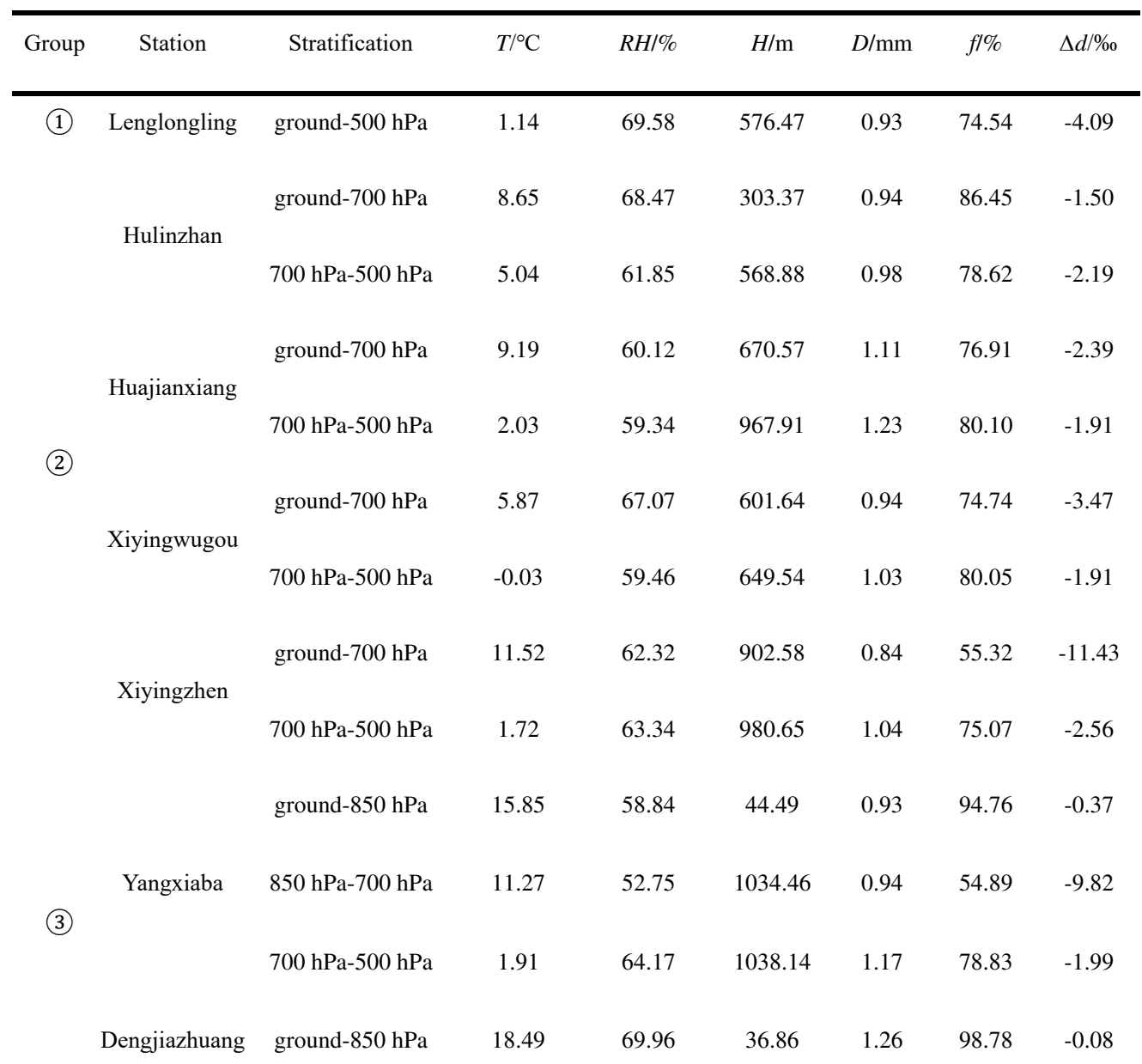




\begin{tabular}{|c|c|c|c|c|c|c|c|}
\hline & $850 \mathrm{hPa}-700 \mathrm{hPa}$ & 14.62 & 60.26 & 713.94 & 1.27 & 77.66 & -2.03 \\
\hline & $700 \mathrm{hPa}-500 \mathrm{hPa}$ & 5.33 & 67.84 & 713.94 & 1.38 & 88.09 & -0.95 \\
\hline & ground- $850 \mathrm{hPa}$ & 21.52 & 71.72 & 23.59 & 1.18 & 98.51 & -0.09 \\
\hline \multirow[t]{3}{*}{ Jiuduntan } & $850 \mathrm{hPa}-700 \mathrm{hPa}$ & 18.35 & 54.58 & 739.99 & 1.18 & 68.27 & -3.78 \\
\hline & $700 \mathrm{hPa}-500 \mathrm{hPa}$ & 7.97 & 65.89 & 762.26 & 1.35 & 84.58 & -1.37 \\
\hline & ground- $850 \mathrm{hPa}$ & 20.21 & 67.07 & 71.51 & 1.01 & 93.98 & -0.44 \\
\hline \multirow[t]{3}{*}{ Xuebaizhen } & $850 \mathrm{hPa}-700 \mathrm{hPa}$ & 17.40 & 63.05 & 765.98 & 1.03 & 66.82 & -4.61 \\
\hline & $700 \mathrm{hPa}-500 \mathrm{hPa}$ & 7.60 & 68.33 & 773.20 & 1.20 & 83.47 & -1.44 \\
\hline & ground- $850 \mathrm{hPa}$ & 19.23 & 58.11 & 58.96 & 1.32 & 97.25 & -0.19 \\
\hline \multirow[t]{3}{*}{ Hongqigu } & $850 \mathrm{hPa}-700 \mathrm{hPa}$ & 14.80 & 55.34 & 865.84 & 1.33 & 72.35 & -3.41 \\
\hline & $700 \mathrm{hPa}-500 \mathrm{hPa}$ & 3.86 & 62.60 & 1006.48 & 1.49 & 84.77 & -1.33 \\
\hline & ground- $850 \mathrm{hPa}$ & 21.35 & 66.73 & 114.04 & 0.94 & 90.45 & -0.66 \\
\hline \multirow[t]{2}{*}{ Datanxiang } & $850 \mathrm{hPa}-700 \mathrm{hPa}$ & 17.04 & 64.66 & 803.61 & 0.97 & 65.24 & -4.49 \\
\hline & $700 \mathrm{hPa}-500 \mathrm{hPa}$ & 7.69 & 63.89 & 818.85 & 1.13 & 78.96 & -1.99 \\
\hline
\end{tabular}

According to the calculation results of the stratification assumption in Table 3 , it can be seen that the $f$ values and the d-excess of the first group (Lenglongling) are relatively low, which indicates the sub-cloud secondary evaporation is strong. This may be related to the raindrop diameter that is the smallest among all sampling points, which is conducive to evaporation. For the sampling points of the secondary group, the $f$ values at $700 \mathrm{hPa}-500 \mathrm{hPa}$ (except for the Hulinzhan) reach the maximum, which indicates the sub-cloud secondary evaporation is weaker. The $f$ value at ground-700 hPa is lower than that at $700 \mathrm{hPa}-500 \mathrm{hPa}$ at Huajianxiang, Xiyingwugou, and Xiyingzhen, indicating that heavy isotope enriches and light isotope deplete, and they further make the $d$-excess decrease, but the opposite for Hulianzhan. Comparing the environmental factors, the temperature, relative humidity and raindrop diameter of the Hulinzhan is highly consistent with other sampling points in the same group, while they have the opposite sub-cloud secondary evaporation, which may be related to the landing height of raindrops. The average raindrop landing height at ground-700 hPa is only $303.37 \mathrm{~m}$ at Hulinzhan, which causes the raindrop landing time to be shorter than other sampling points, so the sub-cloud secondary evaporation is weaker. The changing trends of the $f$ of each sampling point are the same in the third group, that all of them are ground-850 hPa>700 hPa-500 hPa>850 hPa-700 hPa. Comparing environmental factors, it can be seen that this phenomenon is related closely to temperature, raindrop landing height, and raindrop diameter. At ground-850 hPa, the temperature is the highest among the three levels, and the raindrop diameter is the smallest, this creates good conditions for evaporation. However, the landing height of raindrops is the lowest, so the raindrop landing time is the 
shortest and the sub-cloud secondary evaporation effect is weaker. At $700 \mathrm{hPa}-500 \mathrm{hPa}$, the landing height of raindrops is the highest among the three levels and the raindrop landing time is the longest, but the temperature is the lowest and the raindrop diameter is the largest, which is not conducive to evaporation and the sub-cloud secondary evaporation is weaker relatively. At $850 \mathrm{hPa}-700 \mathrm{hPa}$, not only temperature is higher, but also the landing height of raindrops is higher, and the raindrops diameter has not reached the maximum, so the sub-cloud secondary evaporation effect is the strongest.

Because the meteorological elements at different levels and the height of the cloud base are quite different, which makes the sub-cloud secondary evaporation is different, further makes the stable isotopes of precipitation change in the vertical direction. The third group of sampling points is stratified in detail, so the difference of sub-cloud secondary evaporation is more obvious. At the $850 \mathrm{hPa}-700$ $\mathrm{hPa}$, the sub-cloud secondary evaporation is the strongest, indicating that the heavy isotopes of precipitation are most concentrated in this layer. At the $700 \mathrm{hPa}-500 \mathrm{hPa}$, the sub-cloud secondary evaporation is larger, but the evaporation is restricted by the lower temperature, so the stable isotope of precipitation is gradually depleted as the altitude rises and the temperature drops. At the ground- 850 $\mathrm{hPa}$, the $f$ reaches more than $90 \%$, indicating that the sub-cloud secondary evaporation near the ground is weaker. At the same time, the $\Delta d$ of each sampling point at this layer is greater than -1\%o, indicating that the isotope composition of precipitation is less affected by environmental conditions and the change of it is not obvious.

In summary, the natural environment of the sampling points is quite different, and there are differences in the sub-cloud secondary evaporation under the various heights of precipitation, but the overall regular pattern is basically the same. In the Shiyang River Basin, the sub-cloud secondary evaporation is the strongest at $850 \mathrm{hPa}-700 \mathrm{hPa}$, making the heavy isotope of $\delta^{18} \mathrm{O}$ is enriched and the $d$-excess is low. When the air pressure is lower than $700 \mathrm{hPa}$, the sub-cloud secondary evaporation is weak, and the stable isotopes of precipitation continue to deplete as the altitude rises.

\section{Analysis of the moisture source based on wind field and water vapor flux}

This study used the reanalysis data to analyze the geopotential height and wind field at $500 \mathrm{hPa}$ and $700 \mathrm{hPa}$ (Fig.3, Fig.4), the vapor flux fields, and the atmospheric precipitation from the ground to 500 hPa (Fig. 5) during the research period. Then the source of moisture that affects precipitation in the Shiyang River Basin was analyzed in different seasons. 

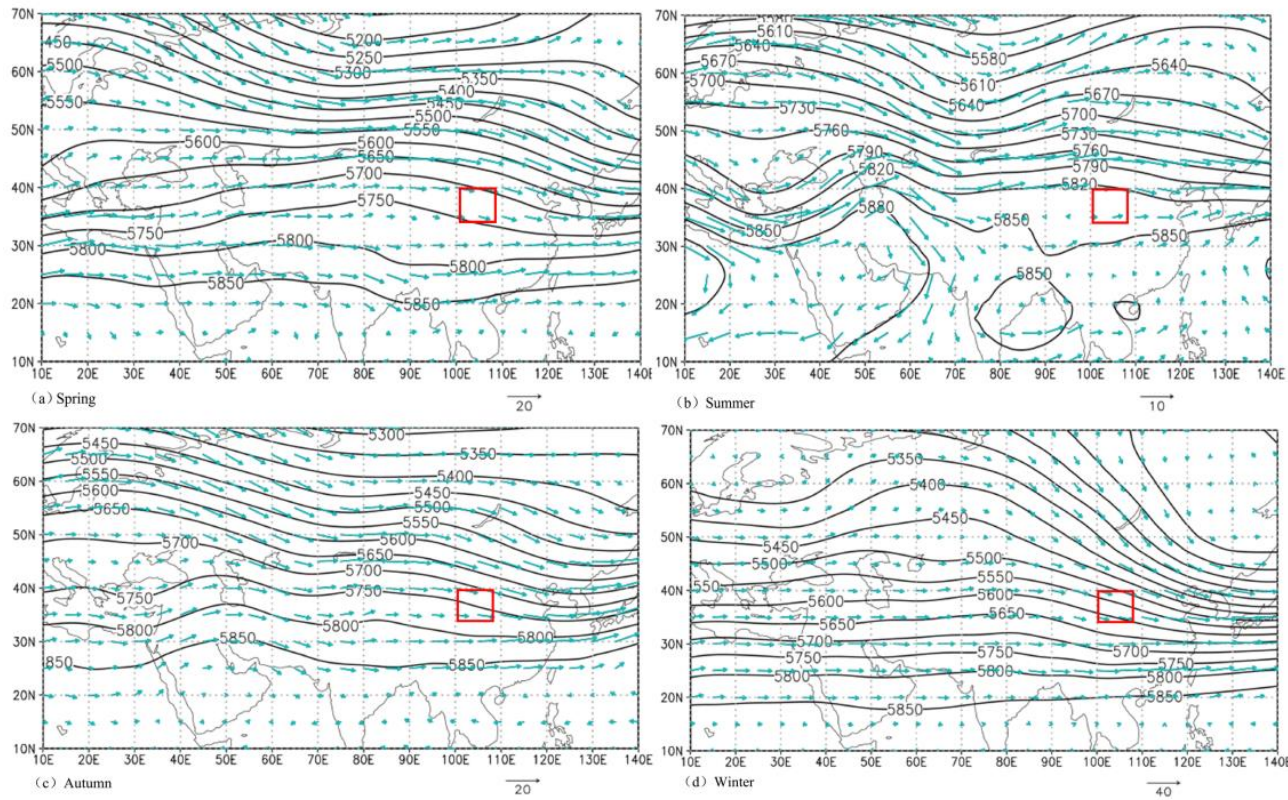

Fig. 3 Geopotential height in geopotential meter (gpm) and wind in $\mathrm{m} / \mathrm{s}$ at $500 \mathrm{hPa}$ in different seasons. Red dashed frames for
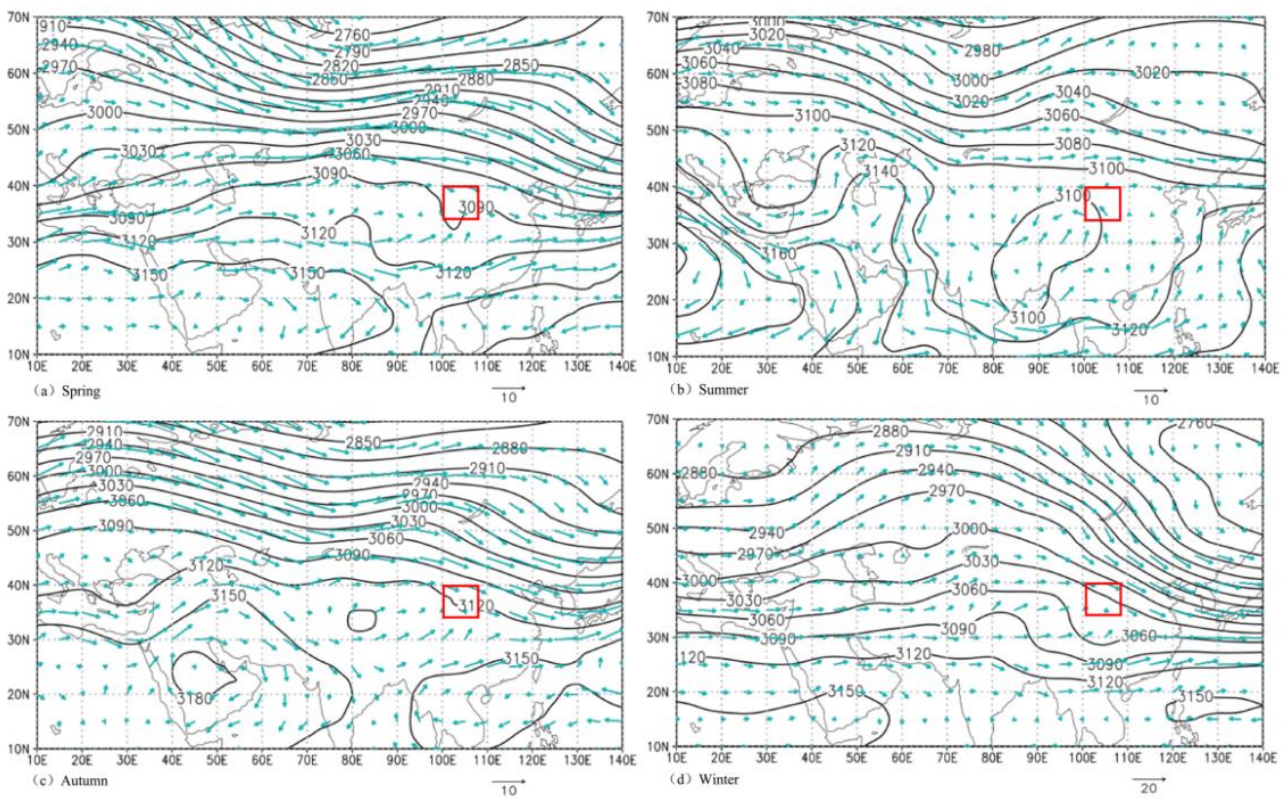

Fig. 4 Geopotential height in geopotential meters (gpm) and wind in $\mathrm{m} / \mathrm{s}$ at $700 \mathrm{hPa}$ in different seasons. Red dashed frames for each subfigure mark the study region.

From Fig. 3 and Fig. 4, it can be seen that the water vapor from westward transport plays a leading role in the Shiyang River Basin, which is consistent with previous studies ${ }^{49}$. At $500 \mathrm{hPa}$ (Fig.3), the geological height contours and wind direction are parallel basically with latitude (except for the summer), and the wind speed has obvious seasonal changes. The wind speed is the largest in winter (40 $\mathrm{m} / \mathrm{s})$, and that is the smallest in summer $(10 \mathrm{~m} / \mathrm{s})$. Although the higher wind speed is conducive to sub-cloud secondary evaporation, the study area is deep inland, and the winter is dominated by dry and 
cold air from the northwest. Therefore, except for the upper mountainous, the precipitation of the winter half-year is sparse and mainly solid precipitation, which causes that the sub-cloud secondary evaporation is generally weaker. At $700 \mathrm{hPa}$, the wind fields are similar relatively in spring, autumn, and winter, and all of which are dominated by westerly winds. The wind speed is highest in winter $(20 \mathrm{~m} / \mathrm{s})$, and it is weaker in spring, summer, and autumn $(10 \mathrm{~m} / \mathrm{s})$. Compared with $500 \mathrm{hPa}$, the geopotential height and wind field at $700 \mathrm{hPa}$ are more complicated, the geopotential height is no longer parallel to the latitude, and even a large closed circulation of low-pressure is formed near the study area in summer, which changes the wind direction. This is mainly affected by the influence of the topography of the Qinghai-Tibet Plateau. The water vapor from the Indian Ocean in summer is blocked and enters the study area along the edge of the Qinghai-Tibet Plateau, which increases the water vapor of relatively humid from the south.
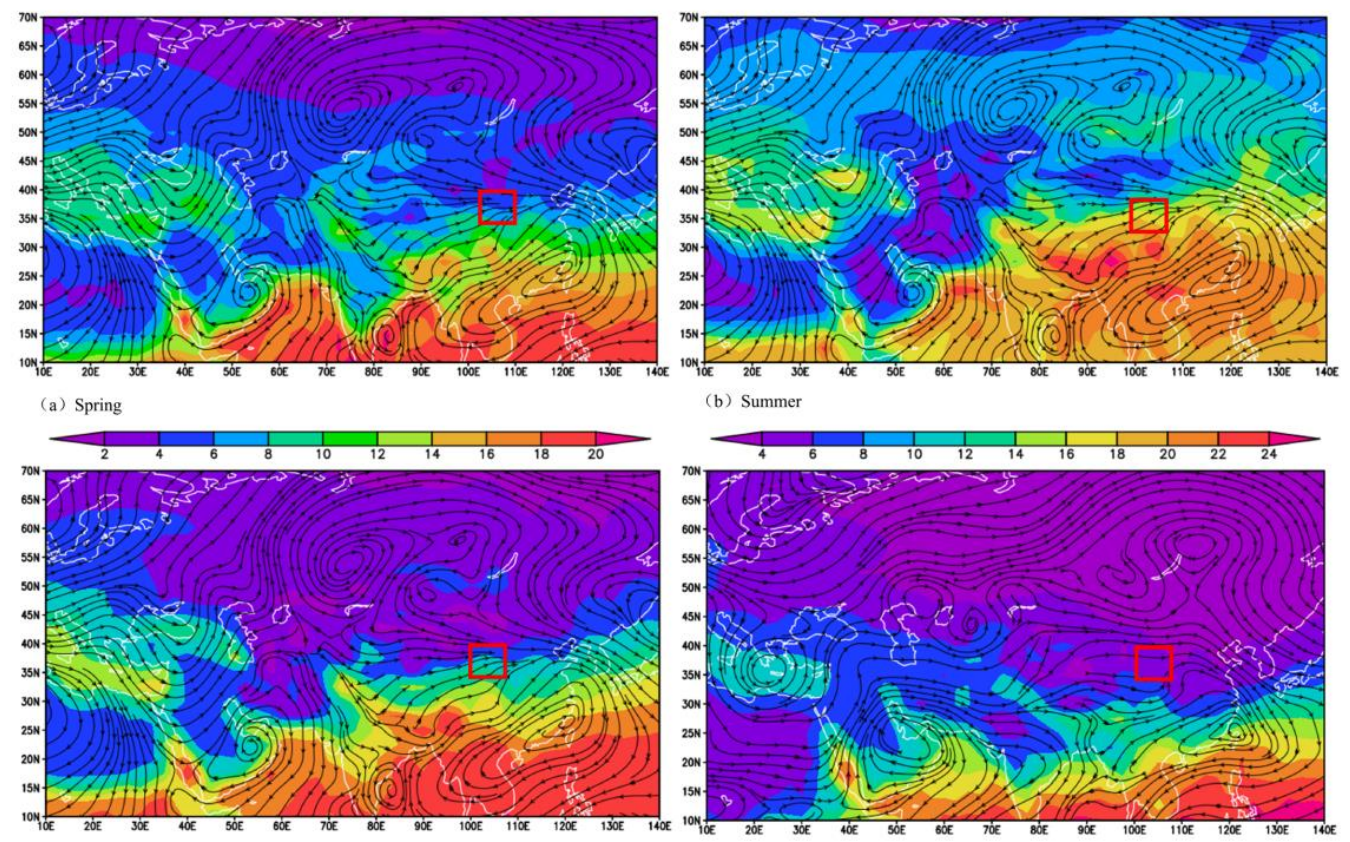

(c)Autumn

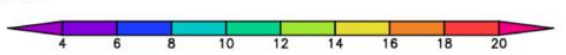

(d) Winter

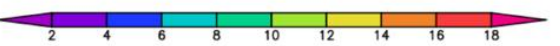

Fig. 5 Water vapor flux streamline and atmospheric precipitation from surface to $500 \mathrm{hPa}$ based on NCEP/NCAR data. Red dashed frames for each subfigure mark the study region.

The seasonal characteristics of heavy isotopes in precipitation enriched in summer and depleted in winter are considered widely to reflect the dominance of westerly water vapor ${ }^{17}$. This understanding is also supported by reanalysis data. It can be seen from Fig. 5 that the Shiyang River Basin is affected by westerly water vapor throughout the year. The atmospheric precipitation and water vapor flux from the ground to $500 \mathrm{hPa}$ have similar seasonal changes. Contrary to winter, the vapor transport is stronger in summer and the atmospheric precipitation is the largest. Considering the relative humidity of water vapor that forms precipitation, the lower $d$-excess in the Shiyang River Basin corresponds to the season when water vapor is replenished in large quantities. That is $d$-excess is lower in summer and higher in winter. However, the increase of recirculated water vapor of inland from local evaporation will lead to 
an increase of $d$-excess, which causes the change of $d$-excess to have no obvious seasonality. This further shows that the stable isotopes of precipitation are affected deeply by sub-cloud secondary evaporation and the moisture source. From the perspective of sea and land sources, natural water bodies such as the Atlantic Ocean, Arctic Ocean, Caspian Sea, and the Black Sea located in the upwind of moisture can be used as potential sources of water vapor. However, it can be seen from Fig.5 that the amount of atmospheric precipitation in these areas is relatively scarce. The Shiyang River Basin is located in the hinterland of Eurasia, and the ocean water vapor carried by the westerly undergoes long-distance transportation, so the supply of precipitation is very limited. As far as the lower part of the atmosphere is concerned, the water vapor channel of the westerly in the northern part of the Shiyang River Basin is more unobstructed, but the water vapor transport in the southern area is affected by the mountain topography is weak. However, compared with the southern mountains, the humidity degree of water vapor transport is lower in the northern, and the amount of atmospheric precipitation is smaller. Therefore, the difference in water vapor transport between them leads to the heavy isotopes of precipitation in the south is more depleted generally than that in the north.

\section{Analysis of the moisture source based on the Lagrangian model with the}

\section{correction of specific humidity}

According to the previous analysis, the source of water vapor is controlled mainly by the westerly in the Shiyang River Basin, but the method of identifying the source of water vapor has limitations by a wide range of vapor flux, which ignores the contribution of evaporation water vapor of local land to precipitation. Relevant studies have shown that the moisture source of precipitation not only comes from transport water vapor and large surface water bodies but also includes a large proportion of local recirculated water vapor, especially in inland arid areas. Local recirculation of water vapor is very important for the replenishment of precipitation ${ }^{56}$. To further clarify the precipitation source of sampling points at different altitudes, this study used Hysplit backward trajectory model to analyze the air masses that affect precipitation in the study area. The spatial resolution of the GDAS data is $1^{\circ} \times 1^{\circ}$, which is not suitable for closer sampling points. Considering the altitude and terrain of the sampling points as well as the distance between them, three sampling points of Lenglongling, Jiuduntan, and Datanxiang in the upstream, midstream and downstream respectively are selected for air mass track.

The residence time of water vapor is generally about 10 days in the stratosphere, but the replenishment of water vapor does not necessarily occur before 10 days. Therefore, this study refers to the research of Crawford et $\mathrm{al}^{57}$, the meteorological elements on the Lagrangian trajectory are also taken into consideration, and the moisture source can be judged from the replenishment intensity of water vapor on the trajectory. In the process of track water vapor, when the specific humidity at the following time interval is $0.1 \mathrm{~g} / \mathrm{kg}$ higher than at the previous time interval, and the simulated height of the air mass trajectory is lower than the planetary boundary layer, it is judged as the source of water vapor. For the calculated multiple sources, the continuous increase of specific humidity and the maximum position of the sum of continuous changes is used as the water vapor source. The starting height of the backward trajectory is the height at which precipitation occurs. In this study, the lifting 
condensation level is used as the starting height, which the specific algorithm refers to equation (7). The cluster analysis of the simulation results of the backward trajectory is carried out to obtain the source direction and weight ratio of the main air masses in different seasons during the sampling period (Fig. 6).
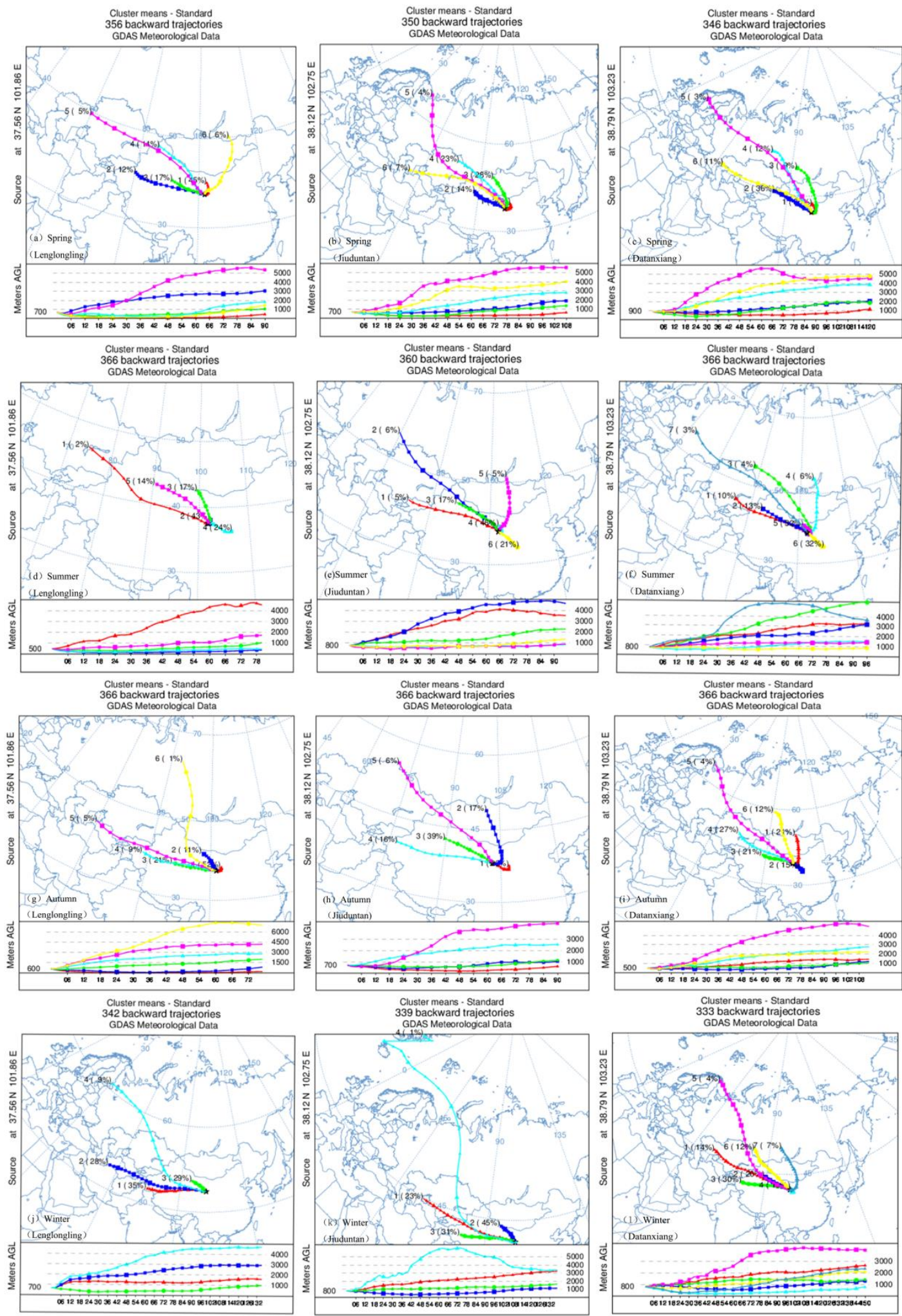

Fig. 6 Cluster analysis of moisture sources in different seasons in the Shiyang River Basin based on the correction of specific 
As shown in Fig. 6, the backtracking path of the air masses corrected by the specific humidity is shortened significantly and the backtracking time has temporal and spatial differences. The backtracking time is shorter in summer and autumn than that in winter and spring. The backtracking time of air mass of Lenglongling is the smallest (3.8 d in spring, $3.3 \mathrm{~d}$ in summer, $3.2 \mathrm{~d}$ in autumn, and $5.6 \mathrm{~d}$ in winter), followed by Jiuduntan ( $4.5 \mathrm{~d}$ in spring, $3.9 \mathrm{~d}$ in summer, $3.7 \mathrm{~d}$ in autumn and $5.7 \mathrm{~d}$ in winter), but that of Datanxiang is the longest ( $5 \mathrm{~d}$ in spring, $4 \mathrm{~d}$ in summer, $4.7 \mathrm{~d}$ in autumn and $6.1 \mathrm{~d}$ in winter), which is affected mainly by the topographical factor of the sampling point. Lenglongling is located in the Qilian Mountains, the transportation of water vapor is prevented by the mountains and is slow relatively. While the terrain of the midstream and downstream is flat, and the transportation of water vapor is fast relatively.

There are certain differences in the moisture sources in different seasons and at different heights. Overall, the analysis results of moisture source direction and water vapor flux have high consistency, that the westward air mass and air mass of mid-high latitude land influence on the Shiyang River Basin, which leads to the changes of stable isotopes in precipitation. According to the source direction and weight ratio of the main air masses in different seasons in Fig. 6, it can be seen that the westerly airflow accounts for a large proportion in each season. The water vapor flux shows that natural water bodies such as the Atlantic Ocean, Arctic Ocean, Caspian Sea, and the Black Sea are all potential sources of moisture, but it is found that the water vapor of the Atlantic and the Black Sea cannot be transported to the study area after correcting the backward trajectory. In addition, the water vapor of the Caspian Sea and the Arctic Ocean has seasonal and accounts for a small proportion of the moisture transport. Therefore, the moisture transport from the sea source has a limited impact on the precipitation in the study area. From Fig. 6, it can be seen that West Asia, Central Asia, and Europe are all in the upwind direction of water vapor. The precipitation in the Shiyang River Basin may be supplemented by water vapor from the land surface in these areas. From the perspective of the backward trajectory of water vapor, there is no air mass from the southwest that transports to the Shiyang River Basin. However, based on the previous analysis of the wind field and water vapor flux, it can be seen that the water vapor of the Bay of Bengal can affect the study area in summer. The reason why it is not reflected in the backward trajectory is that the Qinghai-Tibet Plateau prevents the water vapor of the Indian Ocean from moving northward. However, when the summer monsoon is stronger, the water vapor from the Indian Ocean moves to the northeast along the edge of the Qinghai-Tibet Plateau and enters the Shiyang River Basin from the southeast with the monsoon, which can bring moist water vapor to the study area and make the $d$-excess lower.

By comparing the water vapor sources of precipitation at three selected sampling points in different seasons, it is found that the air mass sources of Jiuduntan and Datanxiang have high similarities, while that of Lenglongling is different from the others. In spring, at the height of 500-2000 $\mathrm{m}$, Lenglongling is not only affected by the same air masses of mid-high latitude continental in the northwest as Jiuduntan and Datanxiang but also affected by air masses from Lake Baikal in the northeast (6\%). At the height above $2000 \mathrm{~m}$, the air masses in Jiuduntan and Datanxiang come mainly from the Caspian Sea, high-latitude land, and polar oceans, that they are transported from the northwest 
to the Shiyang River Basin. In summer, the moisture sources are more diverse, but inland air masses from mid-high latitudes still account for a larger proportion. Besides, there are relatively humid air masses from the southeast monsoon and evaporative supply from inland lakes. The water vapor of $2 \%$ in Lenglongling comes from Lake Balkhash, and Jiuduntan and Datanxiang have water vapor from Lake Baikal, which increases the relative humidity in the study area and decreases the $d$-excess. In autumn, the air mass sources of sampling points have high similarities, especially the height below $3000 \mathrm{~m}$, which they come mainly from the mid-high latitude continental in the northwest and make the $d$-excess higher. In winter, the air masses are still dominated by the mid-high latitude continents to the west, but the transport path of water vapor of Lenglongling increases significantly. The water vapor of long-distance transport makes $\delta \mathrm{D}$ more deplete than $\delta^{18} \mathrm{O}$ and results in $d$-excess lower. In addition, the water vapor of $1 \%$ in Jiuduntan comes from the remote Arctic Ocean, which has a small proportion and long transport distance and has little impact on precipitation.

In summary, the water vapor source of precipitation in the Shiyang River Basin is mainly from the land surface evaporation of mid-high latitude, and the ocean water vapor has little impact on the study area. The water vapor supplied by mid-latitude inland dryness, short transportation distance, low relative humidity, and strong evaporation makes the $d$-excess in precipitation higher. Except for summer, the study area is affected greatly by the cold and dry air of high-latitude, which makes the moisture with lower temperature and relative humidity but higher $d$-excess. In summer, the supply of relatively humid water vapor increases in the Shiyang River Basin, the sub-cloud secondary evaporation is stronger. When the sub-cloud evaporation process occurs, the composition of heavy isotopes in water vapor is lower, but it is higher in the liquid phase $\mathrm{e}^{58}$, which causes the $d$-excess in precipitation to lower in summer. Besides, the water vapor of long-distance transport from the polar ocean makes $\delta \mathrm{D}$ and $\delta^{18} \mathrm{O}$ depleted gradually under the leaching and the strong convective activity. In short, the stable isotopes of precipitation in the Shiyang River Basin are affected by the sub-cloud secondary evaporation and the source of moisture, which makes the $d$-excess show temporal and spatial differences.

\section{Conclusion}

This study verified the existence of sub-cloud secondary evaporation, corrected the moisture source of the study area by specific humidity, and analyzed the influence of sub-cloud secondary evaporation and the moisture source on stable isotopes in precipitation. The main conclusions are as follows:

(1) The Shiyang River Basin exists the sub-cloud secondary evaporation, which is stronger in spring and summer but weaker in autumn and winter, and it is stronger in the midstream and downstream than in the upstream. The heavy isotopes of precipitation in the upstream are more depleted than that in the midstream and downstream. In the vertical direction, the sub-cloud secondary evaporation at 850 $\mathrm{hPa}-700 \mathrm{hPa}$ is the strongest, and the $\delta^{18} \mathrm{O}$ is enriched at this height. When the height exceeds $3000 \mathrm{~m}$, the stable isotopes of precipitation are continuously depleted.

(2) The $d$-excess in precipitation does not show seasonality and regional consistency well. The changing trend of $d$-excess in precipitation is stable relatively in the winter half-year but fluctuates 
greatly in the summer half-year. The $d$-excess in the midstream and downstream is lower than that in the upstream every month, which is related to the sub-cloud secondary evaporation and the different moisture sources.

(3) The moisture source of precipitation in the Shiyang River Basin has temporal and special differences, but it comes mainly from westward air masse. After correction based on specific humidity, the backward trajectory path of the air mass is shortened, the backtracking time is short in summer and autumn but long in winter and spring, and it is longer in the midstream and downstream than the upstream.

(4) The moisture of precipitation in the Shiyang River Basin is affected mainly by inland air masses from mid-high latitudes, while the water vapor from the ocean has little impact on precipitation, which makes the $d$-excess of precipitation larger.

\section{Acknowledgments}

This research was supported by National Natural Science Foundation of China (41661005, 41867030, 41661084), National Natural Science Foundation innovation research group science foundation of China (41421061), and Autonomous project of State Key Laboratory of Cryosphere Sciences (SKLCS-ZZ-2017).

\section{References:}

1. Aemisegger, F., Pfahl, F. \& Sodemann, H. Deuterium excess as a proxy for continental moisture recycling and plant transpiration. Atmospheric Chemistry and Physics 14(8), 4029-4054, https://doi.org/10.5194/acp-14-4029-2014 (2014)

2. Friedman, I. Deuterium content of natural waters and other substance. Geochimica et Cosmochimica Acta 4(1-2), 89-103, https://doi.org/ 89-103.10.1016/0016-7037(53)90066-0 (1953)

3. Craig, H. Isotopic Variations in Meteoric Waters. Science 133(3465), 1702-1703, https://doi.org/10.1126/science.133.3465.1702 (1961)

4. Dansgaard, W. Stable isotope in precipitation. Tellus, 14(4), 436-468, https://doi.org/10.1111/j.2153-3490.1964.tb00181.x (1964)

5. Gu, X. Effects of water vapor transport of Meiyu on stable isotopes in atmospheric wapor in the typical area of the middle and lower reachers of the yangtze River-a case study in Nanjing. Nanjing University. https://doi.org/10.27235/d.cnki.gnjiu.2018.000271 (2018)

6. Wang S. Stable hydrogen and oxygen isotopes in precipitation of the Tianshan Mountains and their significance in hydrological cycle. Northwest Normal University (2015)

7. Schotterer, U., Oldfield, F. \& Fröhlich, K. GNIP: Global Network for Isotopes in Precipitation. 

relationship with water vapor isotopes in the upper reaches of the Urumqi River. Northwest Normal University. https://doi.org/10.27410/d.cnki.gxbfu.2020.000993 (2017)

10. Wang, S. \& Zhang, M. Spatio-temporal characteristics and influencing factors of stable isotopes in precipitation across the chinese tianshan mountains. Quaternary Research 37(5), https://doi.org/10.11928/j.issn.1001-7410.2017.05.19 (2017) waterdrops: Applications to atmospheric processes and evaporation of lakes. Journal of Geophysical Research 80(9), 1133-1146, https://doi.org/10.1029/JC080i009p01133 (1975) regions-moisture recycling. Isotopes in Environmental \& Health Studies 44(1), 61-70, https://doi.org/10.1080/10256010801887208 (2008) of South Australia and its relationship with synoptic weather systems and atmospheric moisture sources. Journal of Geophysical Research: Atmospheres 118(2), 1123-1138, https://doi.org/10.1002/jgrd.50137 (2013) Precipitation of Arid Central Asia and Its Meteorological Controls. Journal of Hydrometeorology 17(7), 1973-1984, https://doi.org/10.1175/JHM-D-15-0203.1 (2016) precipitation isotope in Xinjiang based on the Stewart model improvement scheme. Journal of Glaciology and Geocryology 41(02), 304-315, https://doi.org/ CNKI:SUN:BCDT.0.2019-02-006 (2019) 16. Jiang, Z., Ren, W., Liu, Z. \& Yang, H. Analysis of water vapor transport Characteristics during the

573 Meiyu over the yangtze-huaihe River valley using the Lagrangian method. Acta Meteorologica. Sinica 71(2), 295-304, https://doi.org/10.11676/qxxb2013.017 (2013) 17. Yao, T., Masson-Delmotte, V. \& Gao, J. A review of climatic controls on $\delta^{18} \mathrm{O}$ in precipitation over the Tibetan Plateau: Observations and simulations. Reviews of Geophysics 51, 525-548, https://doi.org/10.1002/rog.20023 (2013) 18. Sodemann, H., Schwierz, C. \& Wernli, H. Interannual variability of Greenland winter precipitation sources: Lagrangian moisture diagnostic and North Atlantic Oscillation influence. Journal of Geophysical Research 113(D3), https://doi.org/10.1029/2007jd008503 (2008)

581 19. Crawford, J., Hollins, S.E. \& Meredith, K.T. Precipitation stable isotope variability and sub-cloud 
582

583

584

585

586

587

588

589

590

591

592

593

594

595

596

597

598

599

600

601

602

603

604

605

606

607

608

609

610

611

612

613

614

615

evaporation processes in a semi-arid region. Hydrological Processes 31(1), 20-34, https://doi.org/10.1002/hyp.10885 (2017)

20. Zhang, B. Study on stable isotope characteristics of meteoric precipitation and water vapor source in Shijiazhuang. Hebei Normal University. https://doi.org/10.27110/d.cnki.ghsfu.2020.001334 (2020)

21. Wei, X., Kang, S., Su, X. \& Chen, J. Impact of oasis agricultural development on the transforming relationship between surface water and and groundwater in the Shiyang River Basin. Transactions of the Chinese Society of Agricultural Engineering 21(005), 38-41, https://doi.org/10.3321/j.issn:1002-6819.2005.05.009 (2005)

22. Zhong, H., Liu, H. \& Gu, Y. On water resources and environment protection of downstream Shiyang river in Minqin down stream. Journal of Water Resources and Water Engineering 13(001), 10-13, https://doi.org/10.3969/j.issn.1672-643X.2002.01.003 (2002)

23. Wang, H., Ning, B. \& Zhang, S. Reasons for the deterioration of ecological environment in Shiyang River Basin and its remedial measures. Gansu Science and Technology 32(03), 10-12+90, https://doi.org/10.3969/j.issn.1000-0952.2016.03.004 (2016)

24. Zhang, L., Zhou, J., Zhang, H., Wang, P. \& Cao, J. Temporal and spatial patterns of climate drought-wet and drought event based on Standard Precipitation Index in Shiyang River Basin. Acta Ecologica Sinica 37(03), 996-1007, https://doi.org/10.5846/stxb201508151709 (2017)

25. Wang, X., Zhang, B., Wang, H., Kang, S.,Wang, M., Li. D. \& Zhang, K. Maximum and minimum temperature changes in Shiyang River Basin in the last 50 years. Arid Land Geography 33(06), 879-888, https://doi.org/10.13826/j.cnki.cn65-1103/x.2010.06.005 (2010)

26. Zhu, F., Xiong, W. \& Wang, K. Water resources in Shiyang River Basin. Gansu people's Publishing House (2010)

27. Sun, J. Analyzing climate cange trends and abrupts in shiyangriver basin for 47 years. Lanzhou University (2008)

28. Kang, S., Su, X. \& Du, T. Water Resources Transformation Law and Water-saving Regulation Mode at Basin Scale in Arid Regions of Northwest China: A Case Study of Shiyang River Basin in Gansu. China Water \& Power Press (2009)

29. Zhong, X. Analysis on Runoff Characteristics of Shiyang River Basin. Gansu Water Resources and Hydropower Technology 47(04), 8-10, https://doi.org/CNKI:SUN:GSSJ.0.2011-04-004 (2011)

30. IAEA (International Atomic Energy Agency). Statistical treatment of data on environmental isotopes in precipitation, Technical reports series No. 331. Vienna, Austria: IAEA (1992)

31. Criss, R.E. Principles of Stable Isotope Distribution. New York, USA: Oxford University (1999)

32. Friedman, I. \& O'Neil, J.R. Compilation of stable isotope fractionation factors of geochemical interest// Data of Geochemistry (1977) 
33. Berberan-Santos, M.N. On the barometric formula. American Journal of Physics 65(05), 404-412, https://doi.org/10.1119/1.18555 (1997)

34. Kinzer, G.D. \& Gunn, R. The Evaporation, Temperature and Thermal Relaxation-Time of Freely Falling Waterdrops. Journal of the Atmospheric Sciences 8(2),71-83, https://doi.org/10.1175/1520-0469(1951)0082.0.CO;2 (1951)

35. Best, A.C. Empirical formulae for the terminal velocity of water drops falling through the atmosphere. Quarterly Journal of the Royal Meteorological Society 76(329), 302-311, https://doi.org/10.1002/qj.49707632905 (1950)

36. Wei, K. \& Lin, R. The influence of the monsoon climate on the isotopic composition of precipition in china. Geochimica (01), 33-41, https://doi.org/10.19700/j.0379-1726.1994.01.004 (1994)

37. Kress, A., Saurer, M. \& Siegwolf, R.T.W. A 350 year drought reconstruction from Alpine tree ring stable isotopes. Global Biogeochemical Cycles 24(2) https://doi.org/24.10.1029/2009GB003613 (2010)

38. Liu, Z., Tian, L. \& Yao, T. Seasonal deuterium excess in Nagqu precipitation: influence of moisture transport and recycling in the middle of Tibetan Plateau. Environmental Geology 55(7), 1501-1506, https://doi.org/10.1007/s00254-007-1100-4 (2008)

39. Zhang, Y., Zhang, M. \& Wang, S. Moisture Source for Short-time Heavy Rainfall in Xinjiang Based on Specific Humidity-adjusted Lagrangian Model. Arid Zone Research 36(03):173-186, https://doi.org/10.13866/j.azr.2019.03.22 (2019)

40. Yuan, R., Jia, W., Li, Z., Xu, X., Zhang, Z., Shi, Y., Ya, L. \& Xiong, H. Precipitation stable isotope regional difference in Shiyang River basin. China Environmental Science 40(11), 4945-4956, https://doi.org/10.19674/j.cnki.issn1000-6923.2020.0547 (2020)

41. Merlivat, L. \& Jouzel, J. Global climatic interpretation of the deuterium-oxygen 18 relationship for precipitation. Journal of Geophysical Research Oceans 84(C8), 5029-5033, https://doi.org/10.1029/JC084iC08p05029 (1979)

42. Jia, G., Yu, X., Fan, D., Zhen, K., Li, Q., Guo, X. \& Zhao, Y. Study on Hydrogen and Oxygen Stable Isotopes in Precipitation in both Sides Along Taihang Mountain. Yellow River 33(07), 34-36, https://doi.org/10.3969/j.issn.1000-1379.2011.07.015 (2011)

43. Shi, M. Intra-event variability of stable hydrogen and oxygen isotopes in precipitation and the relationship with water vapor isotopes in the upper reaches of the Urumqi River. Northwest Normal University. https://doi.org/10.27410/d.cnki.gxbfu.2020.000993 (2020)

44. Froehlich, K., Gibson, J.J. \& Aggarwal, P. Deuterium excess in precipitation and its climatological significance.(2002)

45. Araguás-Araguás, L., Froehlich, K. \& Rozanski, K. Stable isotope composition of precipitation over southeast Asia. Journal of Geophysical Research Atmospheres 103(D22), 28721-28742, https://doi.org/10.1029/98JD02582 (1998) 
651

652

653

654

655

656

657

658

659

660

661

662

663

664

665

666

667

668

669

670

671

672

673

674

675

676

677

678

679

680

681

682

683

684

685

46. Salamalikis, V., Argiriou, A.A. \& Dotsika, E. Isotopic modeling of the sub-cloud evaporation effect in precipitation. Science of the Total Environment 544(feb.15), 1059-1072,

https://doi.org/10.1016/j.scitotenv.2015.11.072 (2016)

47. Ma, X. Stable isotopes in precipitation of the Qilian Mountains and their significance in sub-cloud evaporation. Northwest Normal University. https://doi.org/10.27410/d.cnki.gxbfu.2019.000365 (2019)

48. Yuan, R. Study on stable isotope characteristics and sources of precipitation and river water of Shiyang river basin. Northwest Normal University. https://doi.org/10.27410/d.cnki.gxbfu.2020.001568 (2020)

49. Xu, X. Analyses of regional differences of hydrogen and oxcegen isotopes in precipitation and vapor sources in Shiyang River Basin. Northwest Normal University.

https://doi.org/10.27410/d.cnki.gxbfu.2020.001020 (2020)

50. Gu, X. Effects of water vapor transport of Meiyu on stable isotopes in atmospheric wapor in the typical area of the middle and lower reachers of the yangtze River-a case study in Nanjing. Nanjing University. https://doi.org/10.27235/d.cnki.gnjiu.2018.000271 (2018)

51. Hideaki, M., Naohiko, H. \& Kazuhide, S. Seasonal variations in oxygen isotope ratios of daily collected precipitation and wind drift samples and in the final snow cover at Dome Fuji Station, Antarctica. Journal of Geophysical Research Atmospheres 110(D11), D11106, https://doi,org/110.10.1029/2004JD004953 (2005)

52. Zhang, Y., Xu, Y., Wen, X. \& Su, J. Application of environmental isotopes in water cycle. Advances in Water Science (05), 738-747, https://doi.org/10.3321/j.issn:1001-6791.2006.05.025 (2006)

53. Rozanski, K. Isotope patterns in modern global precipitation, Geophysical Monograph 78. Climate Change in Continental Isotope Records (1993)

54. Peng, H., Mayer, B., Harris, S. \& Krouse, H.R. The influence of below-cloud secondary effects on the stable isotope composition of hydrogen and oxygen in precipitation at Calgary, Alberta, Canada. Tellus B 59(4), 698-704, https://doi.org/10.1111/j.1600-0889.2007.00291.x (2007)

55. Wu, H., Zhang, X.\& Li, X. Seasonal variations of deuterium and oxygen-18 isotopes and their response to moisture source for precipitation events in the subtropical monsoon region. Hydrological Processes 29(1), 90-102, https://doi.org/10.1002/hyp.10132 (2015)

56. Ye, D. \& Fu, Z. Major issues of global change sciences. Chinese Journal of Atmospheric Sciences 18(04), 498-512, https://doi,org/CNKI:SUN:DQXK.0.1994-04-015 (1994)

57. Crawford, J., Hughes, C.E., Parkes, S.D \& Parkes. Is the isotopic composition of event based precipitation driven by moisture source or synoptic scale weather in the Sydney Basin, Australia? Journal of Hydrology 507, 213-226, https://doi.org/10.1016/j.jhydrol.2013.10.031 (2013)

58. Galewsky, J., Steen-Larsen, C.H. \& Field R. D. Stable isotopes in atmospheric water vapor and applications to the hydrologic cycle. Reviews of Geophysics 54(4), 809-865, 
686 https://doi.org/10.1002/2015RG000512 (2016) 


\section{Figures}

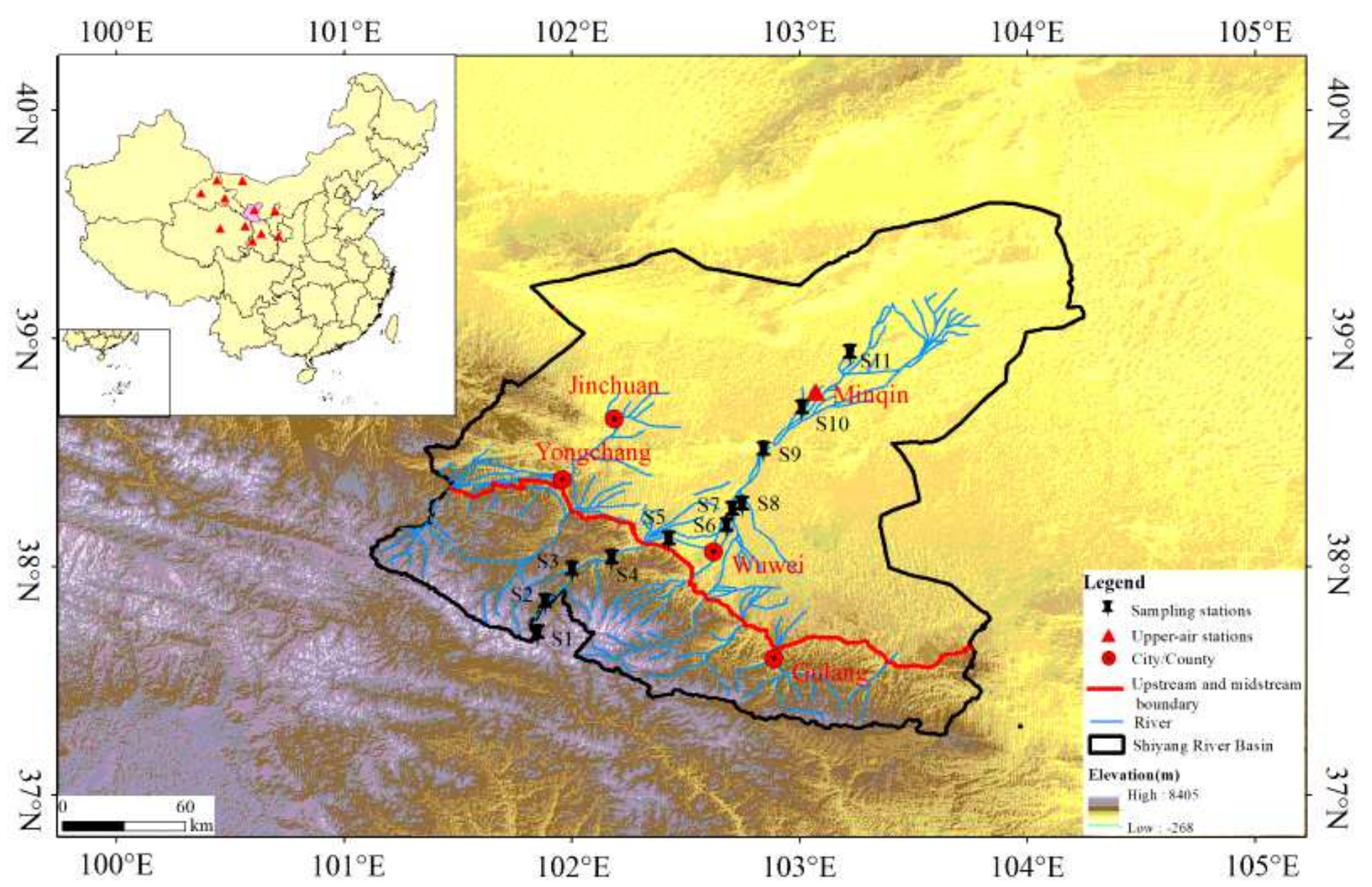

Figure 1

Map showing the locations of sampling sites in the Shiyang River Basin, which are labeled as upstream: Lenglongling (S1), Hulinzhan (S2), Hujianxiang(S3), Xiyingwugou(S4), and midstream and downstream: Xiyingzhen(S5), Yangxiaba(S6), Dengjiazhuang(S7), Jiuduntan(S8), Xuebaizhen(S9), Hongqigu(S10), Datanxiang(S11). Note: The designations employed and the presentation of the material on this map do not imply the expression of any opinion whatsoever on the part of Research Square concerning the legal status of any country, territory, city or area o bbnhjr of its authorities, or concerning the delimitation of its frontiers or boundaries. This map has been provided by the authors. 


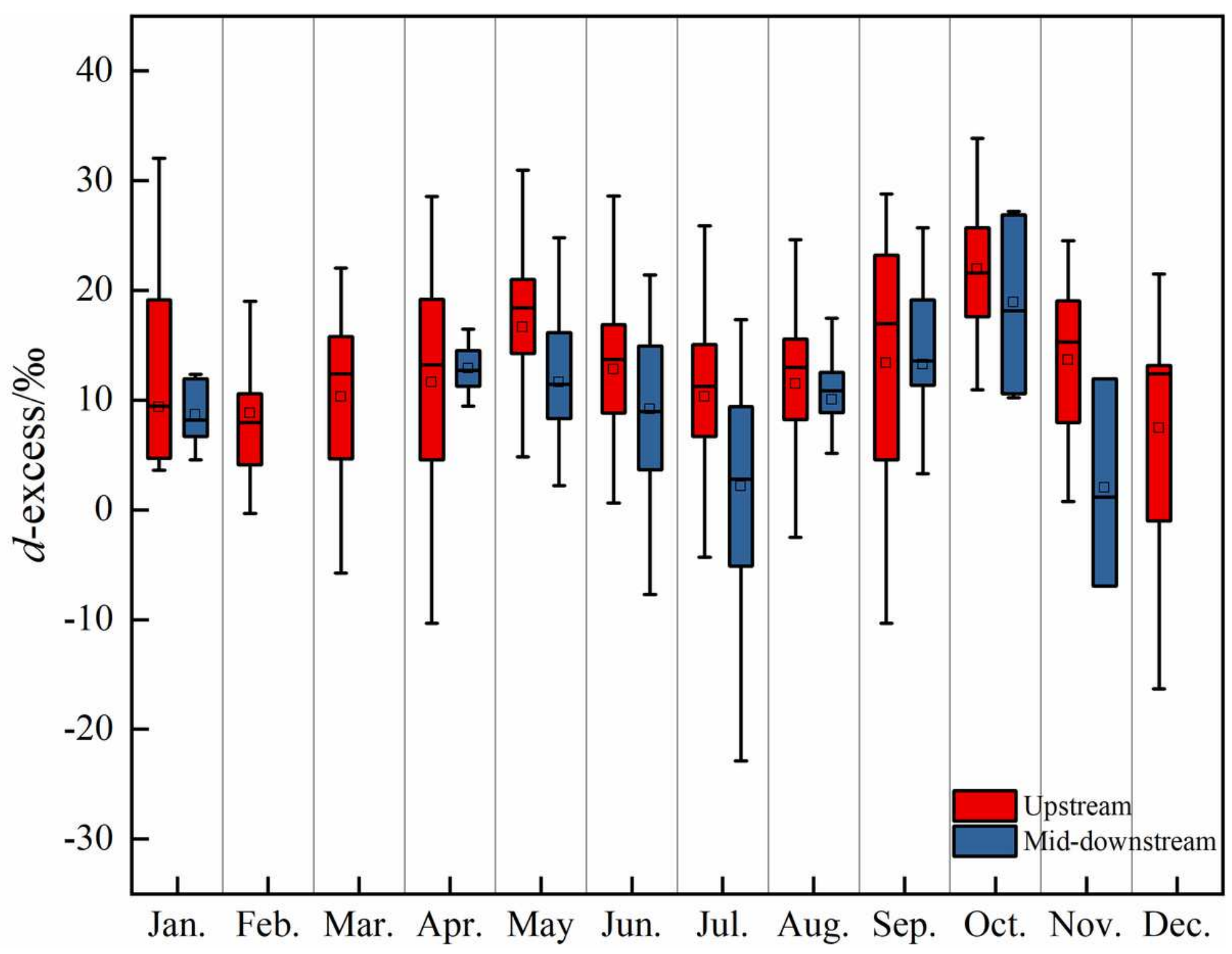

Figure 2

Temporal and spatial changes of d-excess in Shiyang River Basin 

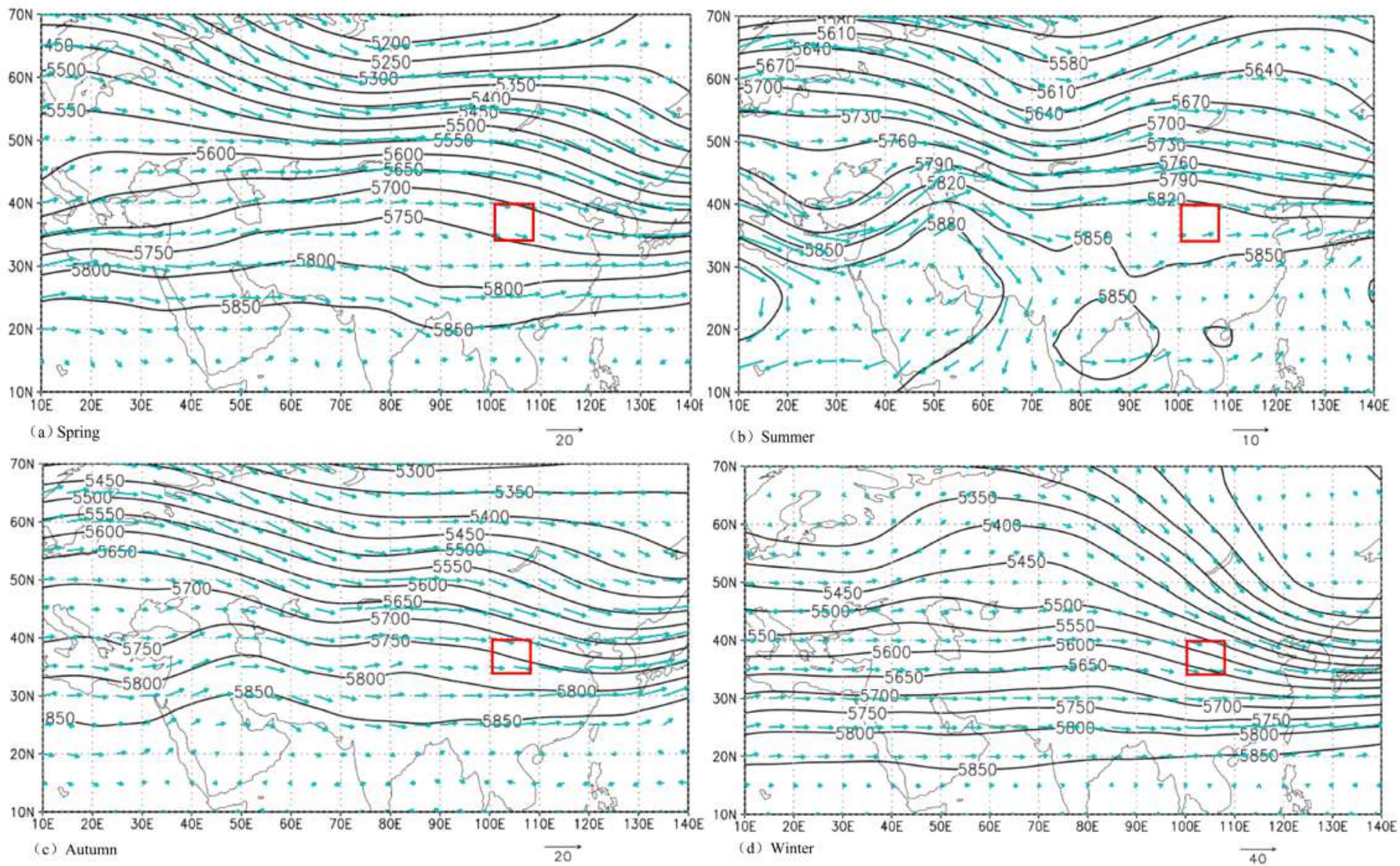

\section{Figure 3}

Geopotential height in geopotential meter (gpm) and wind in $\mathrm{m} / \mathrm{s}$ at $500 \mathrm{hPa}$ in different seasons. Red dashed frames for each subfigure mark the study region.Note: The designations employed and the presentation of the material on this map do not imply the expression of any opinion whatsoever on the part of Research Square concerning the legal status of any country, territory, city or area o bbnhjr of its authorities, or concerning the delimitation of its frontiers or boundaries. This map has been provided by the authors. 

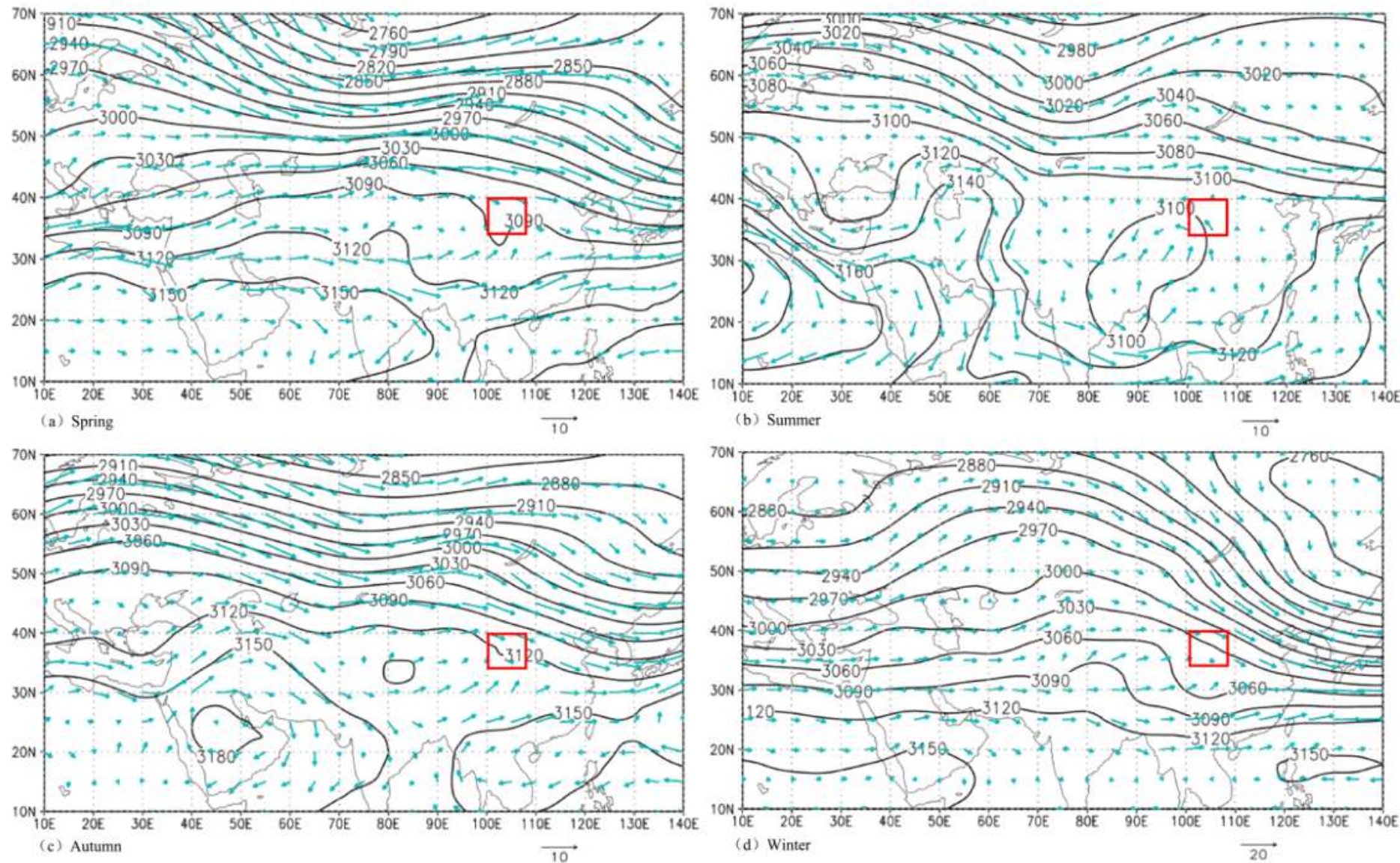

\section{Figure 4}

Geopotential height in geopotential meters (gpm) and wind in $\mathrm{m} / \mathrm{s}$ at $700 \mathrm{hPa}$ in different seasons. Red dashed frames for each subfigure mark the study region. Note: The designations employed and the presentation of the material on this map do not imply the expression of any opinion whatsoever on the part of Research Square concerning the legal status of any country, territory, city or area o bbnhjr of its authorities, or concerning the delimitation of its frontiers or boundaries. This map has been provided by the authors. 

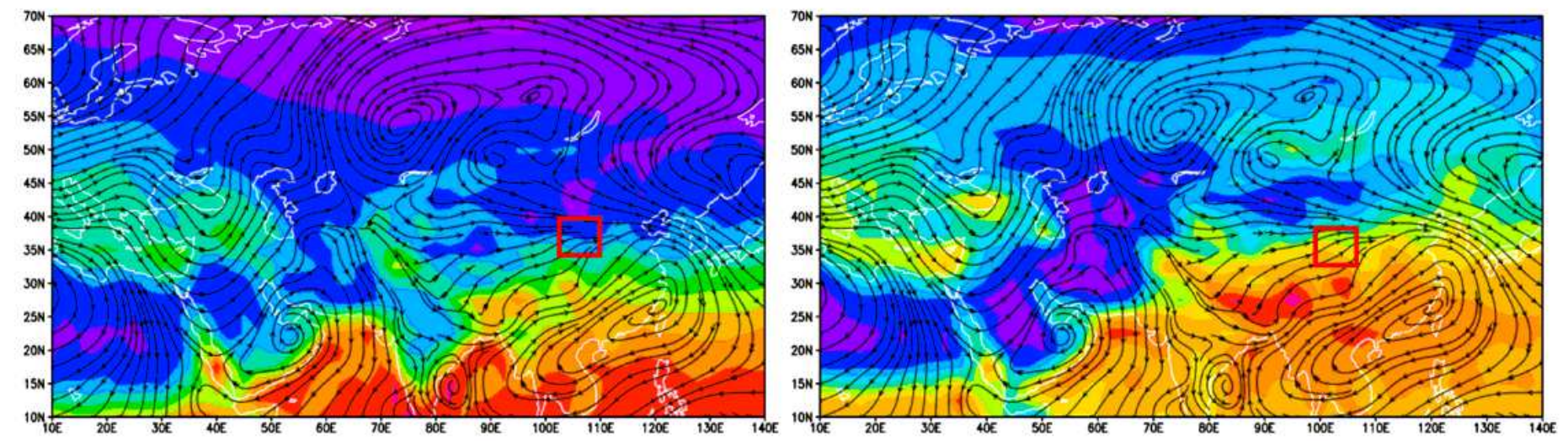

(a) Spring

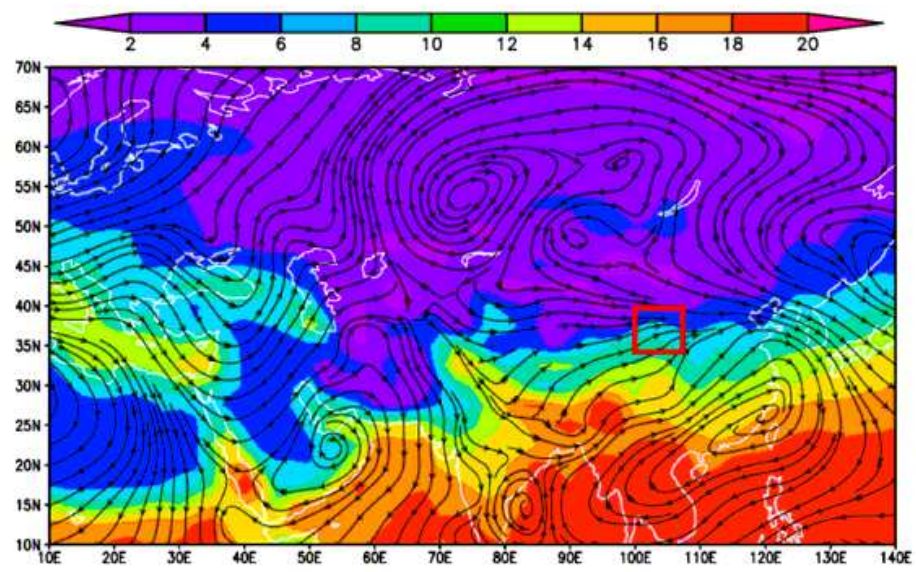

(b) Summer

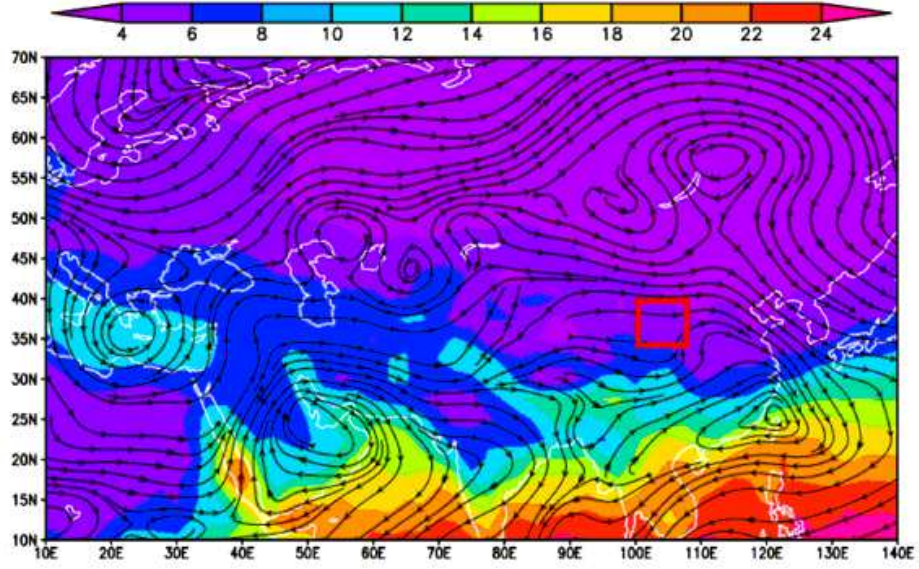

(c)Autumn

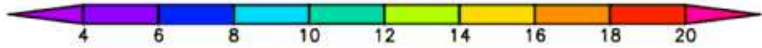

(d) Winter

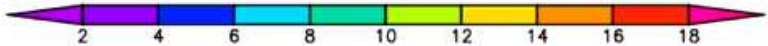

\section{Figure 5}

Water vapor flux streamline and atmospheric precipitation from surface to $500 \mathrm{hPa}$ based on NCEP/NCAR data. Red dashed frames for each subfigure mark the study region. Note: The designations employed and the presentation of the material on this map do not imply the expression of any opinion whatsoever on the part of Research Square concerning the legal status of any country, territory, city or area o bbnhjr of its authorities, or concerning the delimitation of its frontiers or boundaries. This map has been provided by the authors. 

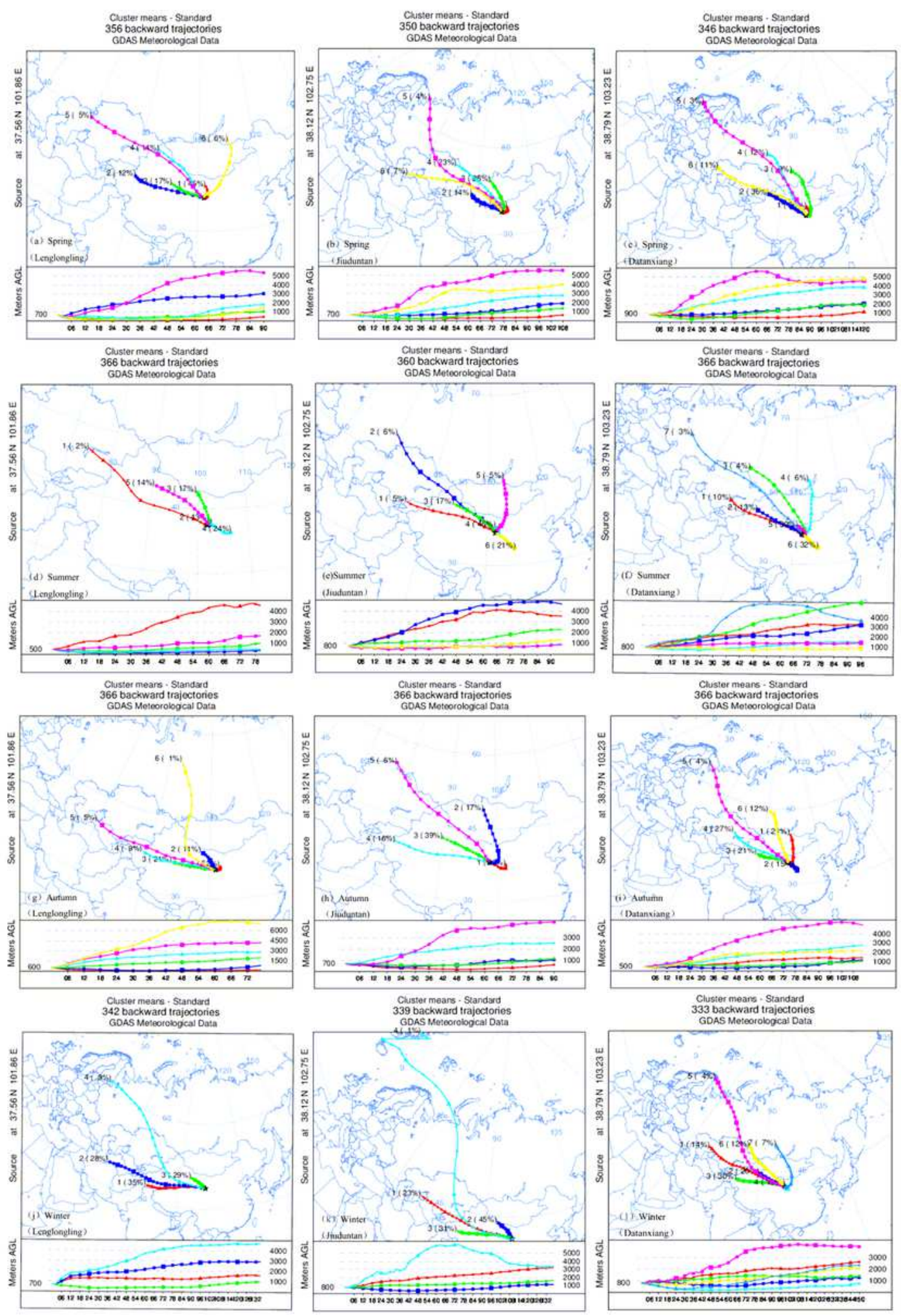

\section{Figure 6}

Cluster analysis of moisture sources in different seasons in the Shiyang River Basin based on the correction of specific humidity. Note: The designations employed and the presentation of the material on this map do not imply the expression of any opinion whatsoever on the part of Research Square concerning the legal status of any country, territory, city or area o bbnhir of its authorities, or concerning the delimitation of its frontiers or boundaries. This map has been provided by the authors. 